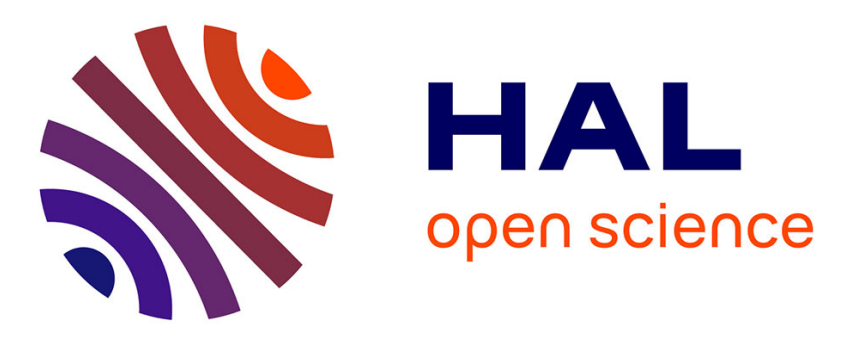

\title{
Environmental Impact Assessment Studies in Additive Manufacturing
}

Olivier Kerbrat, Florent Le Bourhis, Pascal Mognol, Jean-Yves Hascoët

\section{To cite this version:}

Olivier Kerbrat, Florent Le Bourhis, Pascal Mognol, Jean-Yves Hascoët. Environmental Impact Assessment Studies in Additive Manufacturing. Handbook of Sustainability in Additive Manufacturing, 2, pp.31-63, 2016, Environmental Footprints and Eco-design of Products and Processes, 978-981-100606-7. 10.1007/978-981-10-0606-7_2 . hal-01325542

\section{HAL Id: hal-01325542 \\ https://hal.science/hal-01325542}

Submitted on 2 Jun 2016

HAL is a multi-disciplinary open access archive for the deposit and dissemination of scientific research documents, whether they are published or not. The documents may come from teaching and research institutions in France or abroad, or from public or private research centers.
L'archive ouverte pluridisciplinaire HAL, est destinée au dépôt et à la diffusion de documents scientifiques de niveau recherche, publiés ou non, émanant des établissements d'enseignement et de recherche français ou étrangers, des laboratoires publics ou privés. 


\title{
Environmental impact assessment studies in Additive Manufacturing
}

\author{
Dr. Olivier Kerbrat, Dr. Florent Le Bourhis, Pr. Pascal Mognol, Pr. Jean-Yves Hascoët \\ IRCCyN, Institut de Recherche en Communications et Cybernétique de Nantes \\ 1 rue de la Noë \\ BP 92101 \\ 44321 Nantes \\ France \\ Olivier.Kerbrat@irccyn.ec-nantes.fr
}

\begin{abstract}
This chapter focuses on the environmental studies in additive manufacturing.For a cleaner production, environmental impacts that occur during themanufacturing phase should be assessed with accuracy. First, the literature on allthe studies led to the characterization of the environmental impact of additivemanufacturing processes. The studies on electric energy consumption of theseprocesses are analyzed here, and then some studies taking into account raw materialand all the flows through the process are detailed. Secondly, a new methodology inorder to evaluate, with accuracy, the environmental impact of a part from its CADmodel is presented. In this methodology, the work is not focused only on electricalconsumption but also on fluids and material consumption which also contribute tothe environmental impact. In addition, the inputs of this methodology correspond tothe set part process, which allows taking into account different manufacturingstrategies and their influences on the global environmental impact. The methodologydeveloped is based on both analytic models (validated by experiments) andexperimental models. And finally, an industrial example shows that for somemanufacturing strategies, the environmental impact due to electrical consumption isnot the predominant one. In this case study, material consumption has an importantimpact and has to be taken into consideration for a complete environmental impactassessment.
\end{abstract}

\section{Introduction}

This chapter brings an overall view of the environmental impact assessment applied to additive manufacturing processes. As young as the additive processes are compared to more traditional ones, the literature on this topic is relatively recent, but the number of 
publications drastically increases. A whole methodology to assess environmental impact is presented, with a case study in laser cladding, a directed energy deposition process. It is divided into three main sections.

The first section of this chapter is a literature review. The aim of this section is to give a precise view of what has been done when assessing environmental impact in additive manufacturing. It is divided into three sub-sections:

In a first approach, focus is put on studies dealing with electrical energy consumption. The link between manufacturing strategies, part's orientation, process parameters and the whole electrical energy consumption is established, based on a literature review (Luo, Mognol, Bourell, Baumers, Verna, etc.) The objectives of these studies could be to help to compare additive processes between themselves and with more "traditional" processes (machining). At the end of this subsection, a comparative table is given to classify processes and machines considering their Energy Consumption Rate (in $\mathrm{KWh} / \mathrm{kg}$ ).

Secondly, focus is put on material consumption. In fact, additive manufacturing is known to produce parts without lost material. However, a certain amount of material should be removed from the machine or the part at the end of the process. In order to reduce the environmental impact due to this lost material, a few studies (Dotchev, Gornet, etc.) try to develop methodologies to reuse (with or without new raw material) or recycle this raw material.

Finally, some studies evaluate the environmental impact considering both energy, material and fluid consumption. Few methodologies, such as CO2PE! Initiative (Kellens, Duflou, etc.), are based on a global input-output inventory and take into account energy consumption, resource consumption and process emissions.

Based on this state-of-the-art, the second sub-section is constituted by a whole methodology for environmental impact assessment when considering an additive process. The methodology considers the part's design and machine technology. It allows to determine the environmental impact of the set part-process. The methodology is divided into three steps: raw material preparation impact, process impact, lost material recycling impact.

The methodology is based on predictive models that are developed to evaluate the environmental impact of the whole flux consumed (electricity, material and fluids) during all manufacturing steps. The models concern all the features of the machine that contribute to the global environmental impact. It is a local (features) - global (impact) approach, based on an accurate modelling of the process.

Then, the third section is a case study on laser cladding, a directed energy deposition process. Fluid, material and energy consumptions are calculated, directed from the CAD model of the part, in order to establish a predictive environmental impact assessment, during all manufacturing steps (from material extraction to powder recycling). The results can help the designers to choose the best geometry of the part when taken into consideration environmental impact of the product in its manufacturing step. 


\section{Literature review}

\subsection{Introduction}

The first environmental studies on AM processes put forward the possibilities of gain in terms of environmental impact compared with the more traditional processes such as machining [1]. Indeed, only ten years after the development of the first industrial AM machines, studies on the environmental impact of these processes were conducted. This was due to the necessity of taking into account these aspects, with the aim of favoring the large-scale development of the AM processes. AM already offers a new freedom of design, but their industrial development will be more important if these processes have a lesser environmental impact [2].

Five years ago, Hao et al. from the University of Exeter has proposed a study allowing to put forward the possibilities offered by the AM processes to minimize the electric energy consumption during manufacturing[3]. They expressed five major areas for AM to generate positive environmental impacts:

- Material utilization: AM can efficiently utilize raw materials and their functionality. Non-consolidated raw materials in powder based process such as powder bed fusion can be reused so that the material waste can be minimized;

- Product design optimization: the free-form fabrication nature of AM enables optimization in the design of the products. The optimal design will result in the reduction of the materials, energy, fuel or natural resources in the product manufacturing;

- Manufacturing process: The AM has the potential to replace processes where significant amounts of energy are wasted, such as casting or molding. It can also save many resources spent on the fabrication of specific tooling for the production;

- Supply chain: as a direct digital manufacturing approach, the AM machines can be distributed more close to customers and managed by web-based system to coordinate the demands and requirements of product stakeholders and maximize the efficiency of the supply chains. This can reduce the need of long-distance transportation, warehousing, logistics and, for many cases, disposable packaging;

- Life-cycle performance: AM can be used to repair and add advanced functions to existing products as such the life-time performance can be extended.

In this section, we will focus on all the studies led to characterize the environmental impact of AM processes. In a first part, the aspects of electric energy consumption of these processes are analyzed, because most of the studies deal with electric energy consumption. In a second part, we are interested in the works led specifically on the consumption of raw material, because it is one of the main advantages of these processes. In a third part, we will study the few works that take into account all the flows consumed to determine an associated environmental impact. And at the end of this section, we will see the possibilities offered by AM processes on the whole life-cycle of a product. 


\subsection{Electric energy consumption of AM processes}

\subsubsection{First study: Luo et al.}

In a first approach, in order to estimate the environmental performance of AM processes, a number of studies were interested in their electric energy consumption. This first approach allows to compare, on a simple criterion, the AM processes between themselves and even to compare them with the more traditional ones.

The first works led on the energy aspects were conducted by Luo et al. [4][5]. In their studies, the authors compare three SLA machines. An equation gives the scanning speed, a second one gives the process productivity, and then the Energy Consumption Rate (ECR, $\mathrm{kWh} / \mathrm{cm}^{3}$ ) is calculated, and the environmental impact of the energy used to process one $\mathrm{cm}^{3}$ of epoxy resin is obtained (with Eco-indicator index). The results show that the machine with the highest laser power, resulting in the highest scanning speed, has the least ECR.

These first studies are interesting because they propose a first comparison of the processes between themselves. There were completed to compare different machines by Sreenivasan and Bourell [6]. But these studies take into account the energy consumption of the manufacturing processes by considering only the machine, and not all the sensitive parameters (shape of the part, positioning, etc.) that can modify the ECR by modifying the power rate of the machine during the process.

\subsubsection{Influence of the manufacturing orientation}

Most of AM processes use the concept of a layer-by-layer manufacturing. This concept requires the implementation of a slicing of the part to be produces. One of the first studies taking into account the set part-process to determine the electric consumption of an AM machine was proposed by Mognol et al. Indeed, to evaluate the influence of the slicing orientation of the part on the energy consumption of the machine, test parts were produced considering different manufacturing orientation and the electric energy consumption during the manufacturing has been measured. This has been done on three technologies (material extrusion, material jetting and powder-based fusion) [7][8].

Figure 1 illustrates the various orientations of the part taken into account in this study. This work allows to put forward the major influence of the manufacturing orientation on the machine consumption. This most important parameter is the total manufacturing duration, which is strongly dependent on the height to be produced. Therefore, the more important the manufacturing time is, the more important the energy consumption of the machine is. 


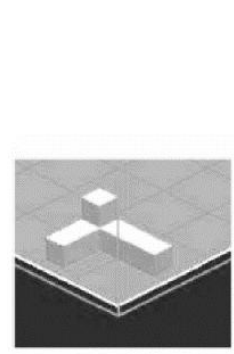

POSITION 1

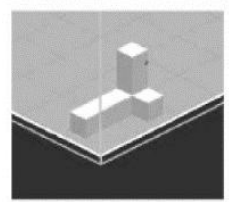

POSITION 4

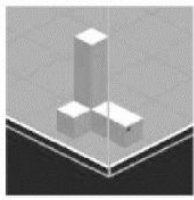

POSITION 7

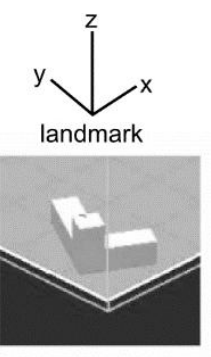

POSITION 2

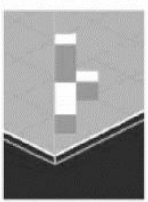

POSITION 5

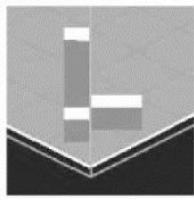

POSITION 9

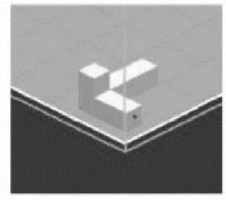

POSITION 3

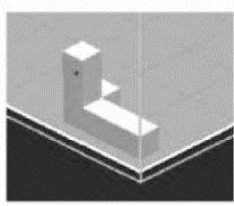

POSITION 6

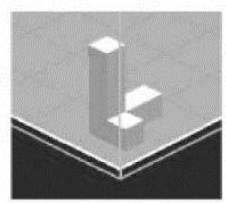

POSITION 8

Figure 1. The various position of the part[8].

On the same criterion of optimization of the manufacturing orientation, Verma and Rai proposed a study allowing to minimize the electric energy consumption and the material consumption, depending on the orientation[9]. The authors has developed a multi-step optimization enabling AM process towards energy efficiency (Figure 2). Process objectives such as material waste and electric consumption are minimized both in part and layer domain.

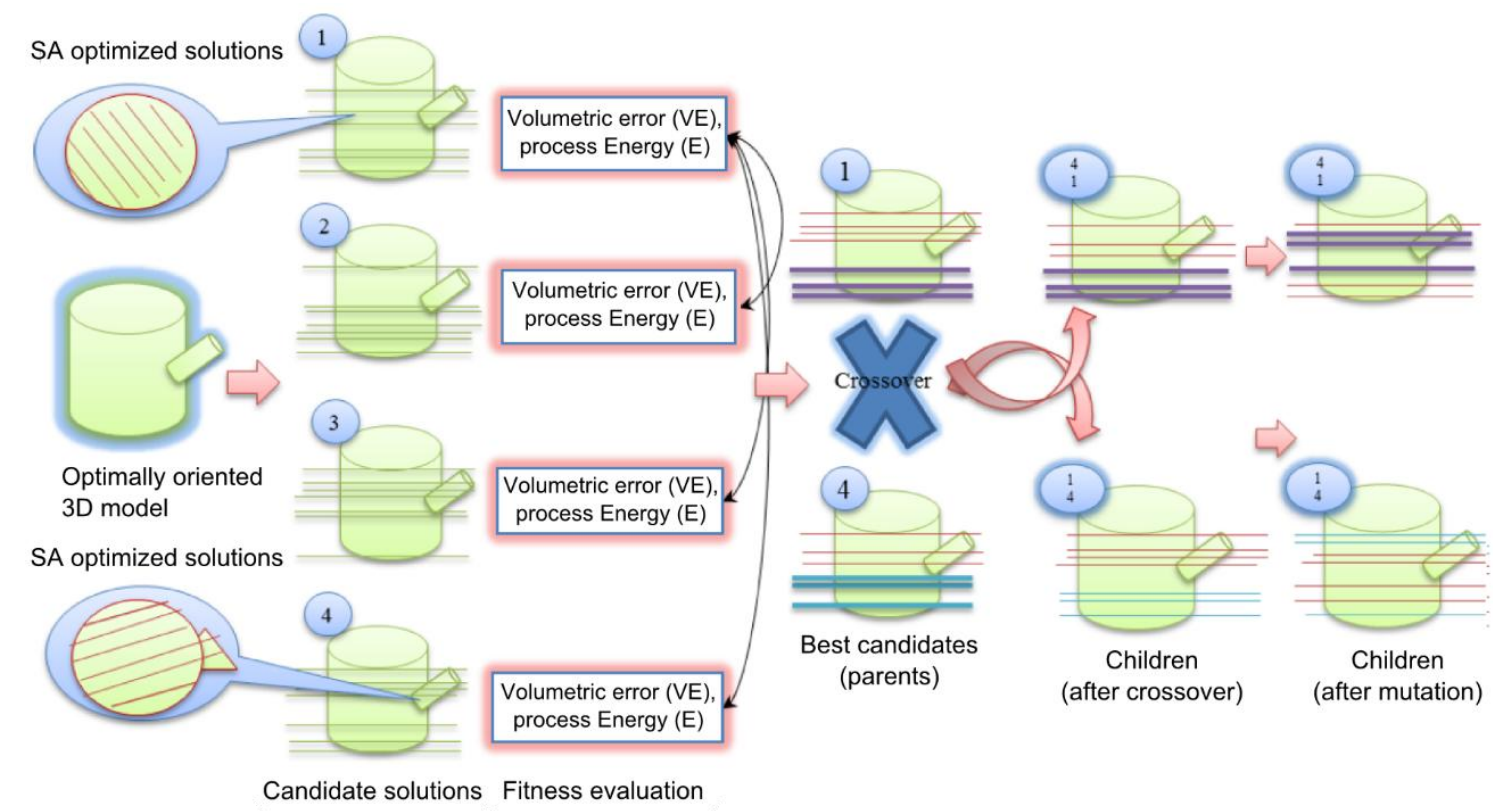

Figure 2. Candidate solution generation and various operators on sample 3D part[9]. 


\subsubsection{Influence of packing density of AM platforms}

Afterward, Baumers et al. studied the influence of the geometry of the part and the packing density of the space machine on the electric energy consumption [10][11]. In their works, they analyzed the energy consumption of two machines, one SLS and one EBM.

The part used for this study is presented in Figure 3. The part geometry was chosen to analyze the influence of the ratio section/volume and perimeter/section on the energy consumption.

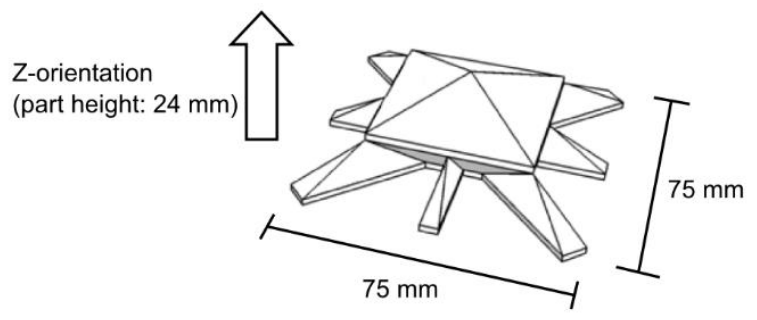

Figure 3. The standardized test part [11].

Furthermore, by analyzing the influence of packing density of the platform (Figure 4) on the energy consumption, the authors show that the consumption is not linked to the number of parts realized. It confirms the others studies showing the energy consumption is strongly dependent on the height of the part.
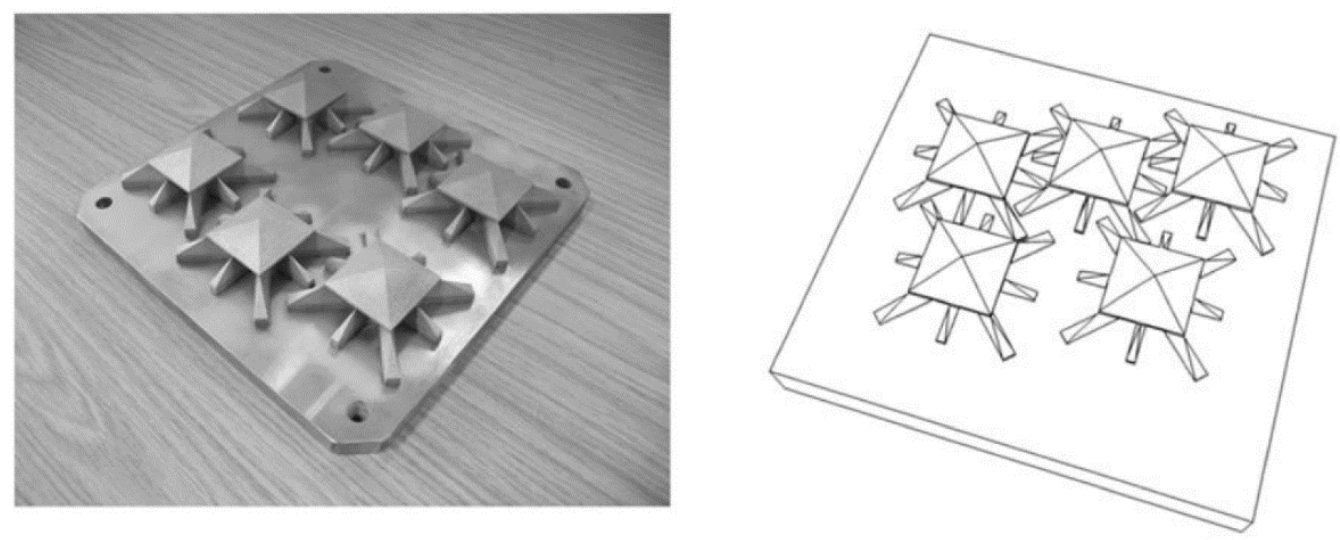

Figure 4. Full build configuration for SLM and DMLS (left) and EBM (right) [11].

The works realized by Mognol and Baumers are very interesting because they highlight the importance of the consideration of the setpart-process within the framework of an analysis of the electric energy consumption of the AM processes.

\subsubsection{Comparison between AM processes and more traditional one}

At first, AM processes essentially allowed to make plastic parts. Therefore, one of the first study led to compare AM with other processes was interested in plastic injection [12][13]. In these studies, Telenko and Seepersad compare both processes with an electric energy consumption point of view. There is a large discrepancy between monetary and energy crossover volumes, this indicates that SLS may be more cost effective than energy efficient in some cases. In fact, the results of this comparative analysis of SLS and injection molding indicate that manufacturers can save energy using SLS for parts with small production 
volumes. Energy crossover production volumes are much larger for a small part, indicating that specific crossover production volumes are sensitive to the size and geometry of the part to produce. Nevertheless, this study does not take into account the manufacturing of the mold. This should be completed to integrate all the necessary data for an environmental analysis.

Atzeni and Salmi evaluate the production volume for which AM processes (selective laser sintering) result competitive with respect to conventional processes (high-pressure diecasting) [14]. In this study, they take into account the possibilities offered by AM (less material, less assembly) (Figure 5). On an example of aircraft part, they conclude that the breakeven point is estimated for a production of 42 components made of aluminum alloy as shown in Figure 6.

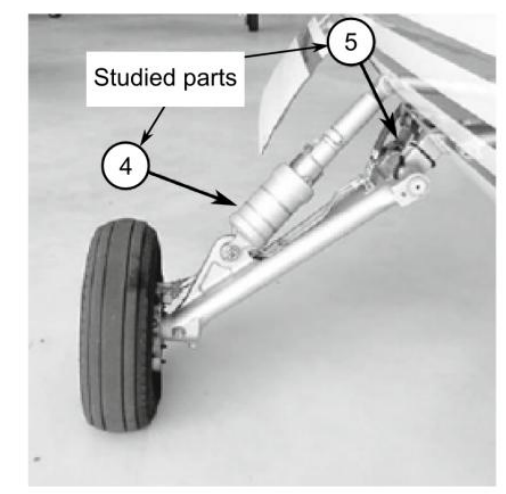

Figure 5. Part for process comparison [14].

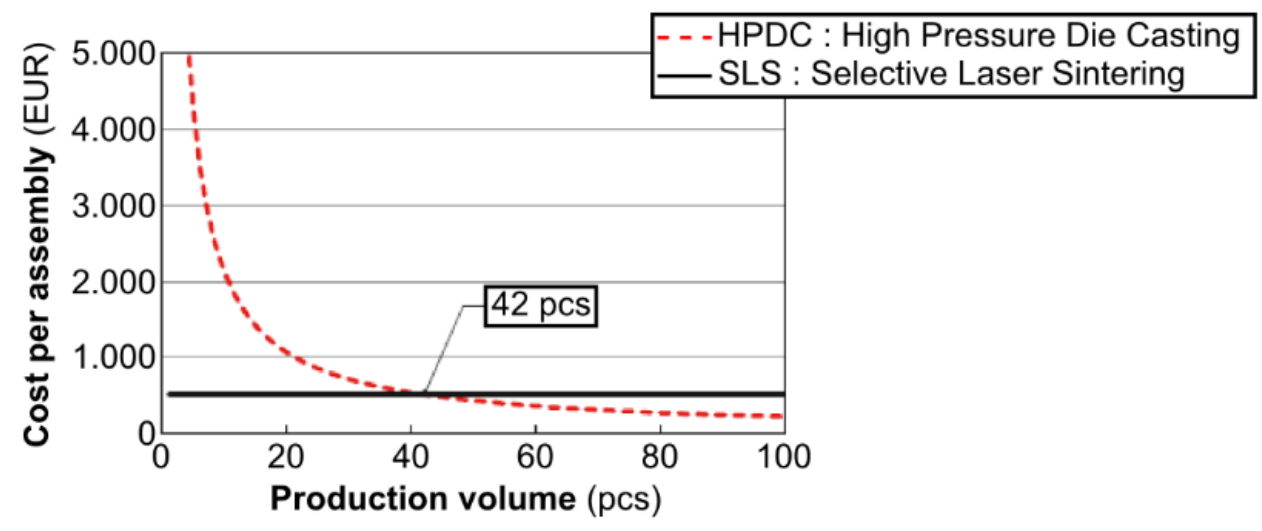

Figure 6. Breakeven analysis comparing conventional high-pressure die-casting and selective maser sintering [14].

In their study, Ruffo et al. compared, with the same criterion, injection molding and AM processes (Figure 7) [15]. Figure 8 evidences different breakeven points between injection molding and $\mathrm{AM}$ techniques for the different cost models utilized, with a comparison to the Hopkinson and Dickens model [16]. The breakeven point moved from 8000 to 14000 parts, for plastic materials. 


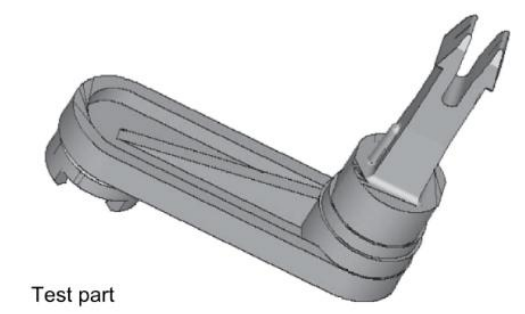

Figure 7. Lever, object of the study [15].

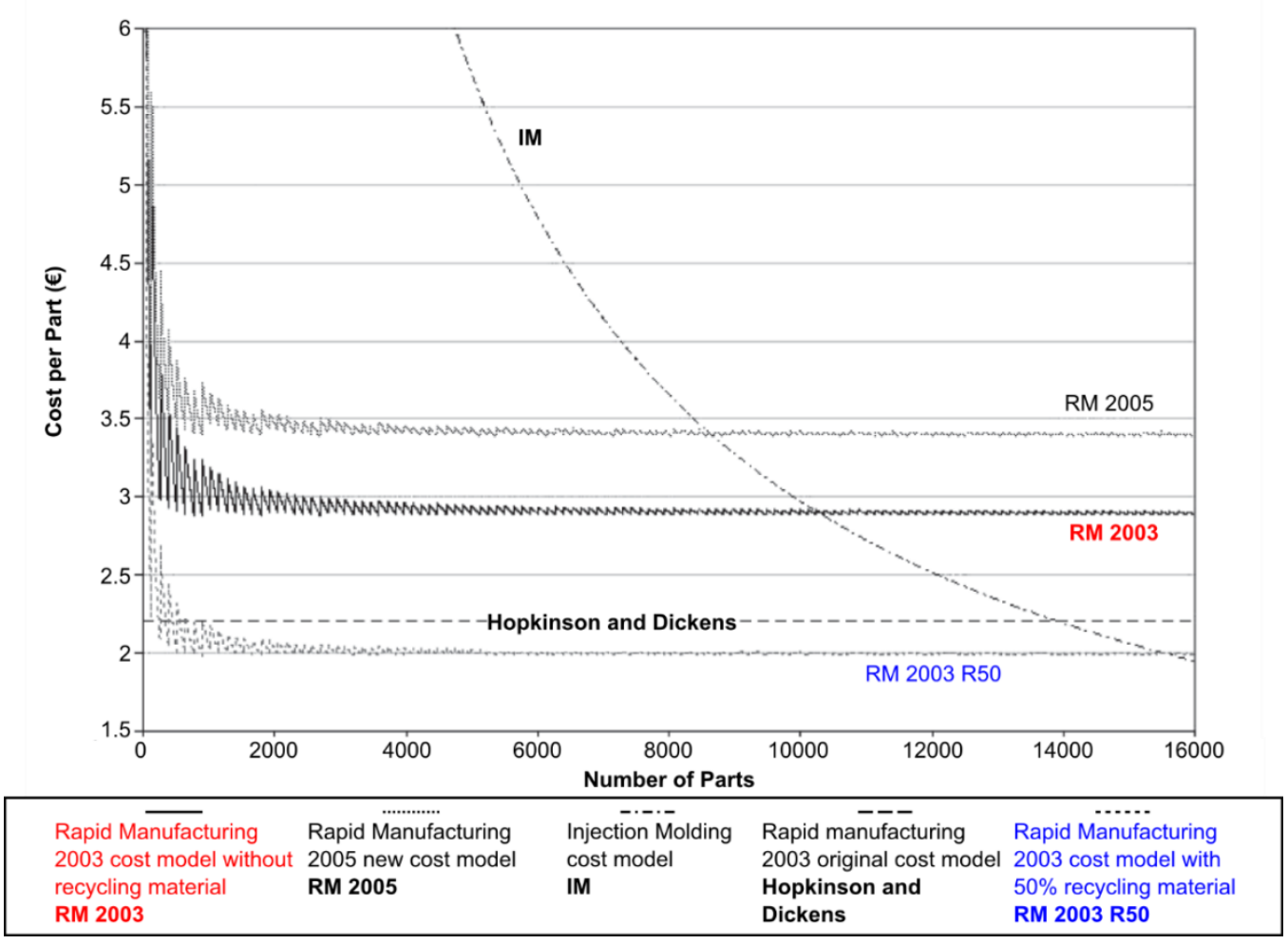

Figure 8. Cost model comparison [15].

With the same process comparison purpose, Morrow et al. provide a study to compare AM with machining [17]. The case studies are on a mold insert and a mirror and reveal that the relative energy consumption of machining versus $A M$ is driven by the solid-to-cavity volume ratio. At low ratios, an AM pathway minimizes energy consumption and emissions, while at high ratios the CNC milling pathway minimizes energy consumption and emissions.

More recently, Serres et al. proposed a study comparing an AM process (CLAD, a directed energy deposition process) and machining on a mechanical part manufacturing out of titanium alloy (Figure 9)[18]. This study helps to highlight that on the whole lifecycle, from raw material extraction to manufacturing, AM reduces about $80 \%$ of the environmental impacts (Figure 10). Nevertheless, this study takes into account only one part geometry for both processes, and does not consider design for manufacturing rules for optimizing geometries with manufacturing point of view. 


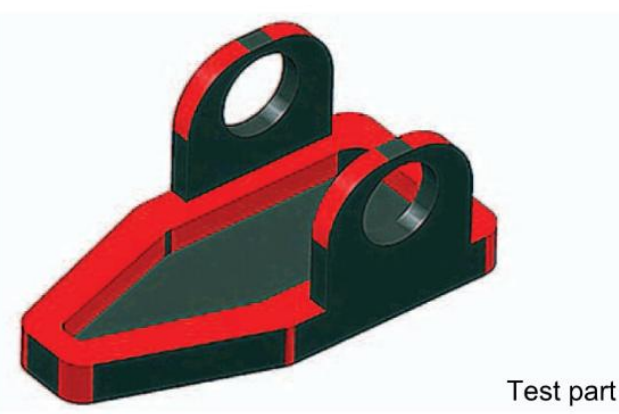

Figure 9. Test-part for the study [18]

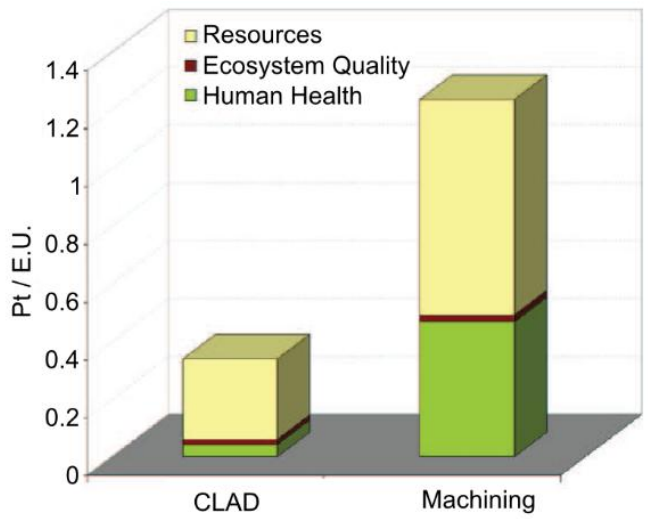

Figure 10. Environmental impacts assessment of the test-part, considering two processes [18].

Recently, Faludi et al. have compared additive manufacturing versus traditional machining via life-cycle assessment [19] and Yoon et al. did a comparison of energy consumption in bulk forming, subtractive and additive processes [20]. They characterized the processes via their Specific Energy Consumption (SEC), in J. $\mathrm{mm}^{-3}$ or $\mathrm{KWh} . \mathrm{kg}^{-1}$. The values of the SEC of similar additive manufacturing processes are so different, with lots of uncertainty on the method of calculation, that it is practically impossible to use SEC for an environmental performance assessment.

\subsubsection{Considering energy consumption and quality of the part}

Of course, a part whose geometric quality does not meet the specifications will not be accepted even if the electric energy consumption during production has been minimized.

Strano et al. have studied the correlation between the final surface roughness of the part produced and the energy consumption of the machine[21]. This study investigates a computational technology for the identification of optimal part orientations for the minimization of surface roughness and simultaneously energy consumption in the manufacturing process. Figure 11 shows the sample geometry to be manufactured and Figure 12 the related optimization, represented by the Pareto set. The results show that, moving along the Pareto front, although most solutions have similar values of energy required to manufacture the part, choosing certain angles allows part quality to be increased considerably. 


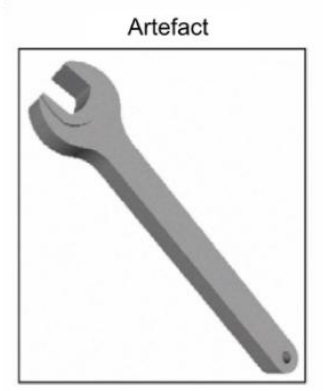

Figure 11. Artefact to be manufactured[21].

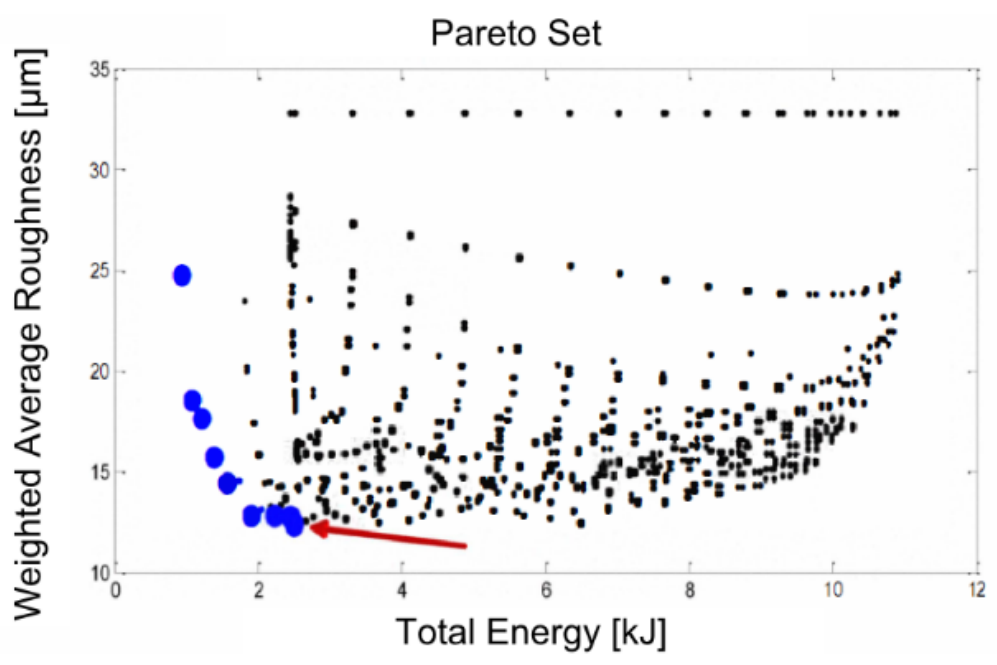

Figure 12. Related Pareto solutions [21].

This study is partially based on the modelling of the surface roughness previously proposed by Campbell et al. [22] and is recently completed in another study by Strano et al. [23].

\subsubsection{Synthesis on electric energy consumption studies}

This section of the literature review refers a number of studies on the electric energy consumption in additive manufacturing processes. It can be seen that it is important to consider the set part-process when characterizing such a process. The morphology of the part produced as well as its position and orientation in the machine space have strong influences on the final results.

Table 1 summarizes all studies concerned with electric energy consumption. The Specific Energy Consumption (SEC, in $\mathrm{KWh} / \mathrm{kg}$ ) is used to compare the different processes. 
Table 1. Comparison of Specific Energy Consumption.

\begin{tabular}{|c|c|c|c|c|c|}
\hline Technology & Machines & Materials & $\begin{array}{c}\text { SEC } \\
(\mathrm{KWh} / \mathrm{kg})\end{array}$ & $\begin{array}{c}\text { Parts } \\
\text { number* }\end{array}$ & Reference \\
\hline \multirow{3}{*}{ Stereolithography } & SLA-250 & $\begin{array}{l}\text { Epoxy resin } \\
\text { SLA } 5170\end{array}$ & 33 & $* * *$ & \multirow{5}{*}[5]{} \\
\hline & SLA-3000 & $\begin{array}{l}\text { Epoxy resin } \\
\text { SLA } 5170\end{array}$ & 41 & $* * *$ & \\
\hline & SLA-5000 & $\begin{array}{l}\text { Epoxy resin } \\
\text { SLA } 5170\end{array}$ & 21 & & \\
\hline \multirow{7}{*}{$\begin{array}{l}\text { Selective laser } \\
\text { sintering }\end{array}$} & $\begin{array}{l}\text { Sinterstation } \\
\text { DTM } 2000\end{array}$ & Polyamide & 40 & $* \star \star$ & \\
\hline & $\begin{array}{l}\text { Sinterstation } \\
\text { DTM } 2500\end{array}$ & Polyamide & 30 & $* * *$ & \\
\hline & Vanguard $\mathrm{HiQ}$ & Polyamide & 15 & ** & [24] \\
\hline & $\begin{array}{c}\text { EOSINT M250 } \\
\text { Xtended }\end{array}$ & $\begin{array}{c}\text { Metallic } \\
\text { powder } \\
(\text { Bronze + } \\
\mathrm{Ni})\end{array}$ & 710 & 1 & [8] \\
\hline & \multirow{3}{*}{ EOSINT P760 } & $\begin{array}{c}\text { Polyamide } \\
\text { PA2200 } \\
\text { Balance } 1.0\end{array}$ & 37 & 63 & \multirow{3}{*}{ [25] } \\
\hline & & $\begin{array}{c}\text { Polyamide } \\
\text { PA2200 } \\
\text { Speed } 1.0\end{array}$ & 40 & 12 & \\
\hline & & $\begin{array}{l}\text { Polyamide } \\
\text { PA3200GF }\end{array}$ & 26 & 11 & \\
\hline \multirow{5}{*}{$\begin{array}{l}\text { Fused deposition } \\
\text { modeling }\end{array}$} & FDM 1650 & ABS plastic & 346 & 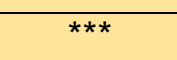 & \multirow{2}{*}[5]{} \\
\hline & FDM 2000 & ABS plastic & 116 & $\star \star \star *$ & \\
\hline & FDM 3000 & ABS plastic & 697 & 1 & [8] \\
\hline & FDM 8000 & ABS plastic & 23 & 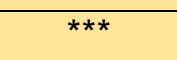 & \multirow{2}{*}{ [5] } \\
\hline & FDM Quantum & ABS & 202 & $* * \star$ & \\
\hline $\begin{array}{l}\text { Selective laser } \\
\text { melting }\end{array}$ & MTT SLM 250 & $\begin{array}{c}\text { Metallic } \\
\text { powder SAE } \\
316 \mathrm{~L}\end{array}$ & 31 & 6 & \multirow{2}{*}{ [10] } \\
\hline $\begin{array}{l}\text { Electron beam } \\
\text { melting }\end{array}$ & Arcam A1 & $\begin{array}{c}\text { Metallic } \\
\text { powder Ti- } \\
6 \mathrm{Al}-4 \mathrm{~V}\end{array}$ & 17 & 5 & \\
\hline
\end{tabular}

${ }^{*}$ Number of parts built in the same time during the experiments

${ }^{* *}$ Fabrication of the entire build volume of the machine $\left(380 \times 330 \times 340 \mathrm{~mm}^{3}\right)$

${ }^{\star * \star}$ Calculation depends on the material flow.

This table allows a first comparison between AM processes. In this table, five technologies have been studied. It is still difficult to make a machine choice, considering which the one with the less environmental impact is, because these machines do not allow to produce parts with identical specifications. For example, stereolithography will produce prototypes whose lifetime is limited, unlike selective laser melting or electron beam melting will realize functional parts, whose lifetime may be well longer. 
This table shows the environmental impact of the manufacturing phase, due to electric energy consumption. However, for a more complete environmental assessment, material consumption have also to be taken into account. That is the main point of the next section.

\subsection{Raw material consumption}

\subsubsection{Introduction}

Additive processes are seen as environmentally interesting because they seem to consume only the required material for the production of the final part. Nevertheless, whatever the technology, it cannot be considered that all the raw material consumed is found on the final part.

In $3 \mathrm{D}$ printing, it is necessary to consider material consumption to create the supports needed to manufacture the part. These supports will be subsequently removed either by dissolving or manually. Similarly, when using selective laser melting technology, an amount of the powder present in the workspace may not be reused [26]. Inpowder bed or powder projection technologies, a part of the deposed material is not fused, and it is necessary to consider this raw material lost in the environmental analysis. In powder bed, all the powder present in the workspace is not merged, fused or sintered and could require a postmanufacturing treatment to be reused.

\subsubsection{Powders recycling}

The use of plastic (and, of course, metallic) powders require some attention. In fact, plastics powders are sensitive to aging which reduce their mechanical properties [27].

To avoid premature aging of plastic powders, Dotchev et al. have developed a methodology to recycle the un-sintered powders [26]. In this study, they analyze the influence of the recycled powder rate mixed with fresh powder on the final part quality. The objective is to limit the "orange peel" texture on the parts produced.Finally, they define a methodology that could improve the powder quality control, minimize the part quality variation, and reduce the amount of fresh powder used in laser sintering process.

Metallic powders may be sensitive to the moisture contained in the air, causing their oxidation. Usually, the non-fused powder is reused after sieving treatment, and few studies are focused on recycling the metallic powder in AM processes.

\subsection{Other flows that impact the environment}

The environmental performance assessment of a manufacturing process must necessary take into account all of the flows through the process (input and output). Even if AM processes use less consumables than most conventional ones, it is therefore not possible to assess the environmental performance by considering only the electric energy consumption. The quantity of raw material used as well as waste produced during the process, all the fluids such as inert gas to prevent oxidation and cooling fluids for the machine must also be taken into account because they contribute to the overall environmental impact.

Kellens et al. have developed the UPLCI (Unit Process Life-Cycle Inventory) methodology for systematic analysis of manufacturing process [28]. They applied it on selective laser sintering process [29][30][31]. This methodology takes into account all the flows through the system. They analyze the electric energy consumption, compressed air 
consumption, and material consumption and take into consideration the environmental impact due to powder, consumables, and emission. Figure 13 shows a schematic overview of the parametric estimation model for SLS process.

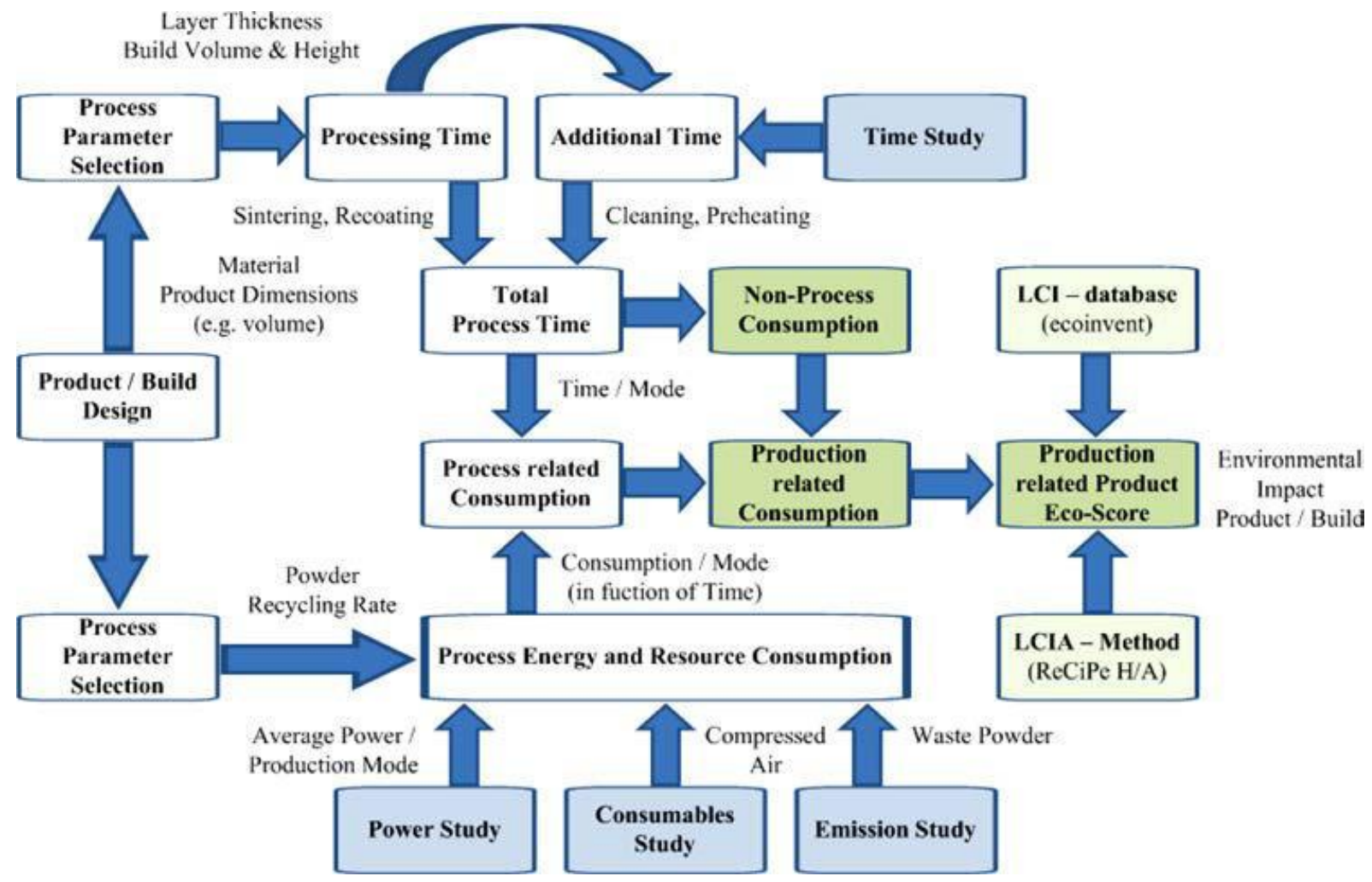

Figure 13. Overview of the parametric impact estimation model for SLS process [31].

The methodology developed by Kellens et al. allows to comment, analyze and improve the process knowledge, especially for manufacturing prototypes or small batch size. The knowledge generated by this methodology allows to bring data on manufacturing processes to LCA databases [32]. In their work, the UPLCI methodology is applied on additive manufacturing, laser cutting and EDM. Finally, it proposes new ways to improve these processes from an environmental point of view, based on both the electric energy consumption and on the material consumption, but also on the architecture of the machines.

Similarly, Verma and Rai offer a study, also cited in section 2.2.2, oriented not only on the optimization of energy consumption but also focused on material consumption [9]. Considering these two consumption factors, they set up a multi-objective optimization to minimize overall material consumption and power consumption. Furthermore, they impose a certain quality of the part by coupling the aforementioned minimization of consumption with maximizing the surface quality (controlled by the surface roughness). In this study, they set up a double loop optimization. Initially, they optimize the overall part minimizing the amount of raw material and surface roughness. Secondly, they optimize, for every slice of the part, the electric energy consumption. Figure 14 summarizes the optimization algorithm. 


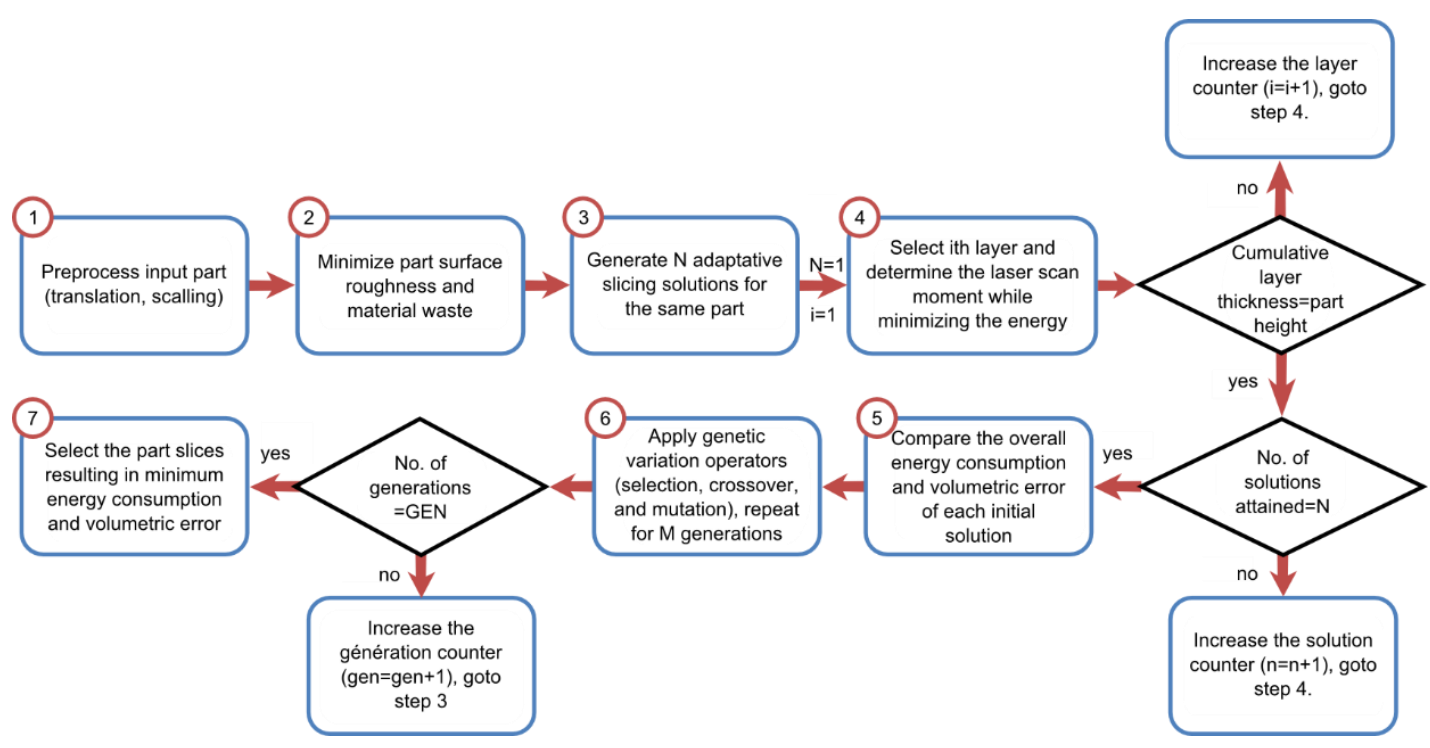

Figure 14. The developed optimization framework for adaptive slicing [9].

This consideration of all consumption flow is an essential step for the characterization of manufacturing processes. Studies taking into account these remarks are very recent and need to be developed with further investigations.

\subsection{Possibilities offered by AM processes on the whole life-cycle of a product.}

The studies presented in the previous sections are generally centered on the process. These studies help to compare the manufacturing processes between themselves, allowing to make a choice on the most environmentally friendly technology in the manufacturing stage. But even if the environmental impact due to the manufacturing phase may be important, it may be negligible when considering the whole life-cycle of the part. On this point, additive manufacturing may offer interesting design of parts, from an environmental point of view, on the whole life-cycle. In this case, analyzing the possibilities offered by additive manufacturing process, such as topology optimization, optimized design minimizing mass, multi-function integration, etc., could help designers to create an additive manufactured part with less environmental impacts than a machined one.

The collaborative project Atkins was interested in this issue [33][34]. In this project, the authors studied all the possibilities for reducing the environmental impact of parts produced by AM processes. Apart from the already mentioned advantages in design, AM also reduces the availability time and the impacts generated by transportation (from production stage place to use stage place). Indeed, manufacturing facilities can be built close to the use stage location. The part to produce is sent as a numerical file and will be realized close to the place of consumption. Then, this reduces the environmental impact causes by the transportation stage, which is a source of significant environmental impacts. Manufacturing companies also take advantages from additive manufacturing because they need very little time to adapt their production chain at the market; the changeover time is considerably reduced.

The Atkins project helped to highlight the possibilities of $A M$ in order to minimize the overall environmental impact of a product. Moreover, as a result of the project, a software tool was developed as a guide in the choice of processes, with purposes to minimize the environmental impact or the economic impact. One of the major conclusions of this project is 
that additive manufacturing can be greatly benefit in the aeronautic and transport fields, because of the mass minimization opportunities for embedded parts.

\subsection{Synthesis of the literature review}

Efforts to characterize the environmental performance of AM processes have often focused on the electric energy consumption. In this section different studies were analyzed. One can realized that only few studies concerned with the raw material consumption or fluid consumption for these processes.

This lack of data is probably due to the youth of AM processes. However, as it has already been noted in this section, it is important, in the environmental analysis context, to take into account all the flows through the process in order to precisely assess its environmental performance.

\section{Environmental impact assessment methodology}

\subsection{Introduction}

In the third part of this chapter, a methodology to assess the environmental impacts of an additive manufacturing process is presented.

In the next section, as a general approach of the process leading to produce a mechanical part, all the life-cycle stages of the part (from raw material to end-of-life) must be taken into consideration to correctly evaluate the environmental impacts.

In a third section, manufacturing process is the main point. AM process modeling from an environmental point of view is done. The environmental impacts generated at this stage are mainly due to the resource consumption (material, electric, etc.) and waste production (support, etc.) An approach coupling all consumptions is presented.

Finally, the fourth section will summarize the contributions of such a methodology.

\subsection{General approach}

The methodology for evaluating the environmental impacts of AM processes that is presented in this chapter aims to raise the scientific locks that have been outlined in the literature review.

This methodology, based on an accurate knowledge on manufacturing processes, allows to analyze the environmental performance and takes into account two aspects. The first one is interested in the whole life-cycle stages of the part (Figure 15). The second is focused on the process has for objectives to estimate quantitatively all the resources consumption of the set part-process (Figure 16).

The production of mechanical products is generally made by the succession of stages. Indeed, parts are rarely produced directly by using only one single process. Figure 15 shows one of these stages sequencing. 


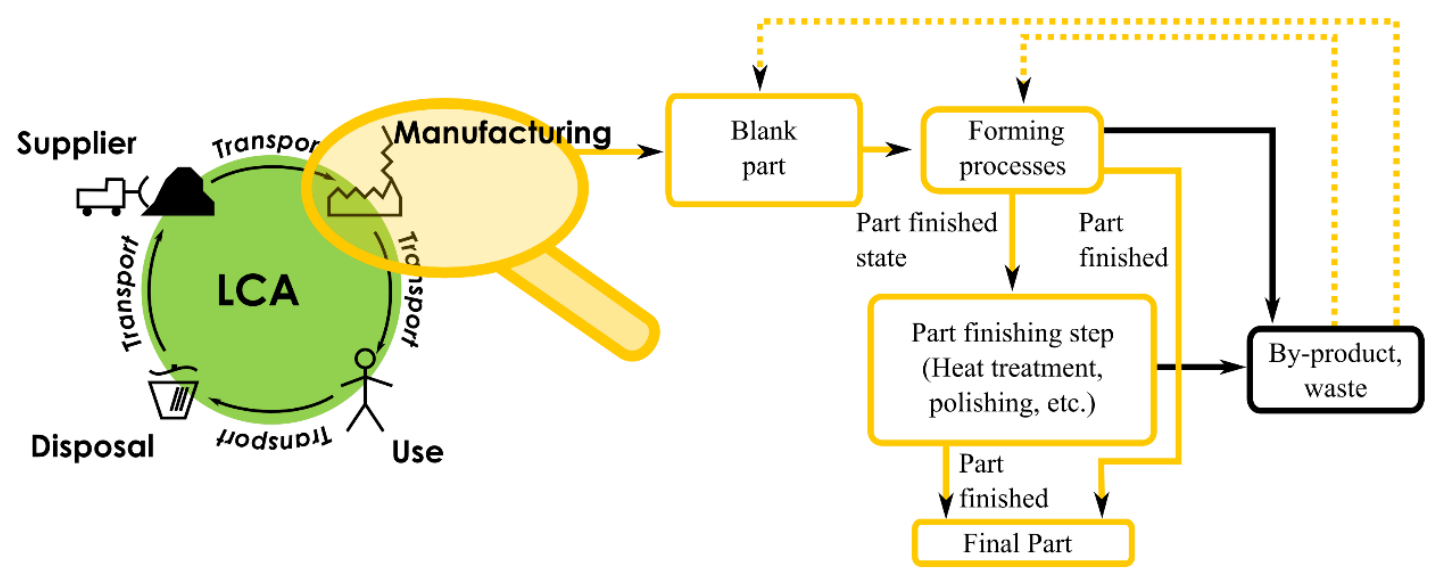

Figure 15. Life-cycle stages and the manufacturing phase.

It is thus necessary to take into account all the stages needed for the manufacturing of the part. Indeed, a vision being interested only on one stage can lead to a wrong analysis because the environmental impacts which could be minimized during a stage can be drastically increased in another one. For instance, when considering a directed energy deposition process such as projection of powders, it seems little sensible to be interested only in the manufacturing stage without being concerned in the stage of production of powder or the finishing post-process. That is why, a global approach, as proposed by life-cycle analysis, must be used to estimate the environmental performance of a manufacturing process.

Then the proposed methodology is thus interested in all the stages of manufacturing a product. In particular, the stages taken into account are listed below.

- Raw material production. In AM process, raw material are most of times plastic filament, plastic or metallic powder, liquid resin.

- Shaping. This stage consists, thanks to a set of manufacturing sub-stages, in transforming the raw material, obtained in the previous stage, into a finished or semifinished part.

- Post-processing. This last stage allows to obtain the final dimensions and expected characteristics of the part. For example, it concerns the support removal operations, some finishing processes such as machining, polishing or laser polishing, etc.

- Waste recycling. This waste can be of various: material such as unsintered powder or support material, fluids needed during manufacturing, etc.

The knowledge of all manufacturing stages is essential to propose a global and accurate assessment of environmental impacts. From this knowledge, it is then possible to define a modeling of each stages in an environmental point of view. This is the main topic of the next section.

\subsection{Manufacturing process modeling}

\subsubsection{Framework and limits}

In life-cycle analysis, data concerning the manufacturing processes could be extracted from databases (for instance, Ecoinvent). What is found in these databases is just a 
macroscopic vision of the processes, with a global average value for characterizing each process. Now this global vision does not allow to take into account the influence of the manufacturing parameters (strategies, feed rate, temperature, etc.) on the final energy consumption. So these data often suffer from accuracy. Furthermore, they are only a "picture" of a process and do not allow to put forward the relation between manufacturing parameters, the part to produced and the total environmental impact. And AM process are still not referenced in such databases.

Therefore, a modeling of the manufacturing stages, taking into account all input parameters of the machine is necessary. The objective of this model is at first to be able to predict all the consumptions generating impact during the process, and then, secondly, to set up a minimization loop by modifying design parameters or manufacturing parameters.

Figure 16presents the global vision of the developed methodology. The figure illustrates the necessity of taking into account all the flows of materials, energies and information in the manufacturing stages modeling.

From the well-detailed knowledge of the manufacturing process, translated as predictive models, it is then possible to link part design and environmental impacts during manufacturing. The aim is thus to link the environmental impact due to the part production to its numerical model.

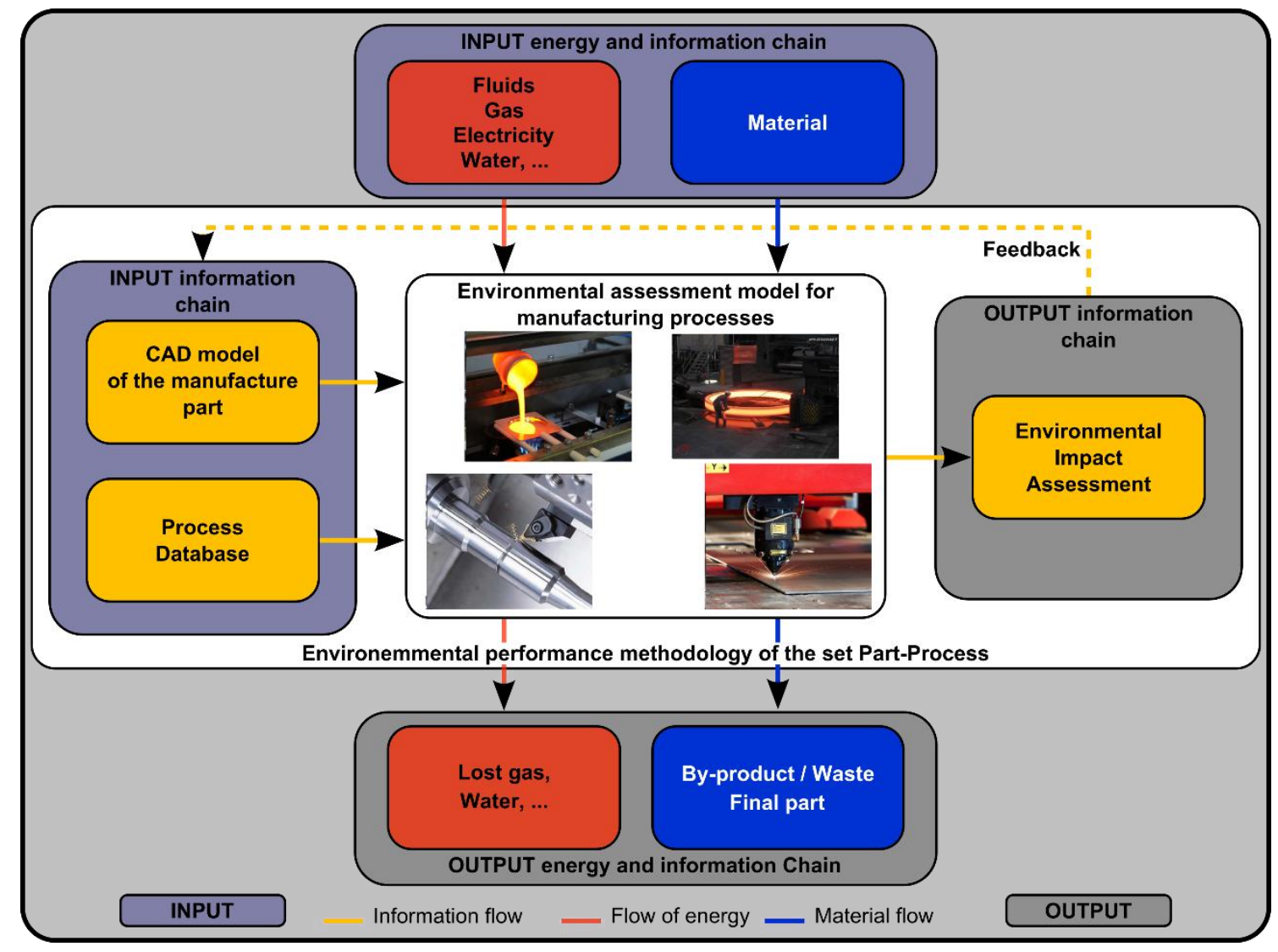

Figure 16. Methodology for assessing environmental impact of a set part-process.

The first stage necessary is to define all the flows which will be taken into account and consequently the limits of the study. Indeed, in the developed methodology, even if it has been suggested to take all the flows, it is quite evident that certain limits must be put before completing the study. 
Figure 17 shows the limits imposed on manufacturing process, in case of a directed energy deposition process. Similar limits may be easily constructed for other processes. In this figure, it can be noticed that the consumptions of inert gas, compressed air, hydraulic fluids, metallic powders as well as electricity are taken into account during the environmental impact assessment. It is important to underline that the chosen limits are similar to the "system boundaries" as defined in the standard ISO 14955-1, Machine tools - Environmental evaluation of machine tools, Part 1: Design methodology for energy-efficient machine tools[35]. Indeed, the inert gas production, hydraulic fluids production and compressed air production are not included in the system boundaries. The manufacturing of the machine is also not under the scope of the study. It would be possible to extrapolate the study by including the production of all the inputs and the manufacturing of the machine. It would be interesting because such a study would allow to show that an optimal choice of components (axes motor drives, for instance) as well as the architecture of the machine allow to optimize its energy consumption during its use phase (when manufacturing a product). These studies are already conducted by Kroll et al. [36] or Nuyen et al. [37].

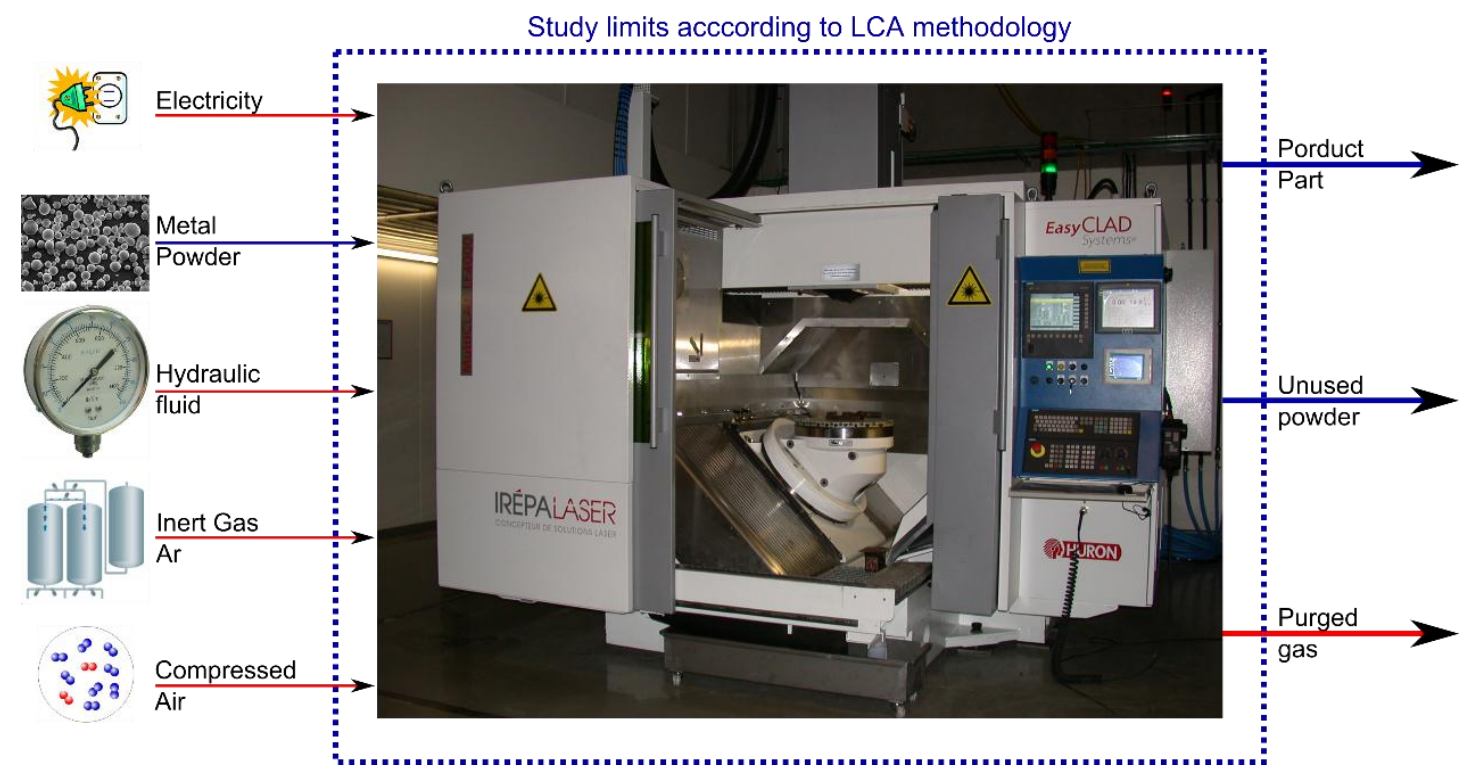

Figure 17. Directed energy deposition (CLAD) process.

\subsubsection{Input data}

In the methodology, the goal is to remain centered on the set part-process. Indeed, based on the literature review in the previous section, geometry of the part as well as its positioning in the machine workspace could influence the process consumptions in terms of material or energy.

The major input data of the methodology is the numerical model (CAD model) of the part. It could allow to modify its geometry, and furthermore, it is possible to advise designers with a software tool which will indicate the areas of the part for which the environmental impact could be optimized.

The second input data is based on a well-detailed knowledge of the manufacturing process, more specially the process parameters, path trajectories, axes motor drives, cooling unit system, etc. This knowledge is stored in a database, defining the AM process in the set part-process, which will be used during the environmental impact assessment. 


\subsubsection{A multi-step methodology}

Figure 18 presents a global view of the developed methodology. This methodology has for objective to link the environmental impact (output) to the numerical model (input) in a set part-process approach.

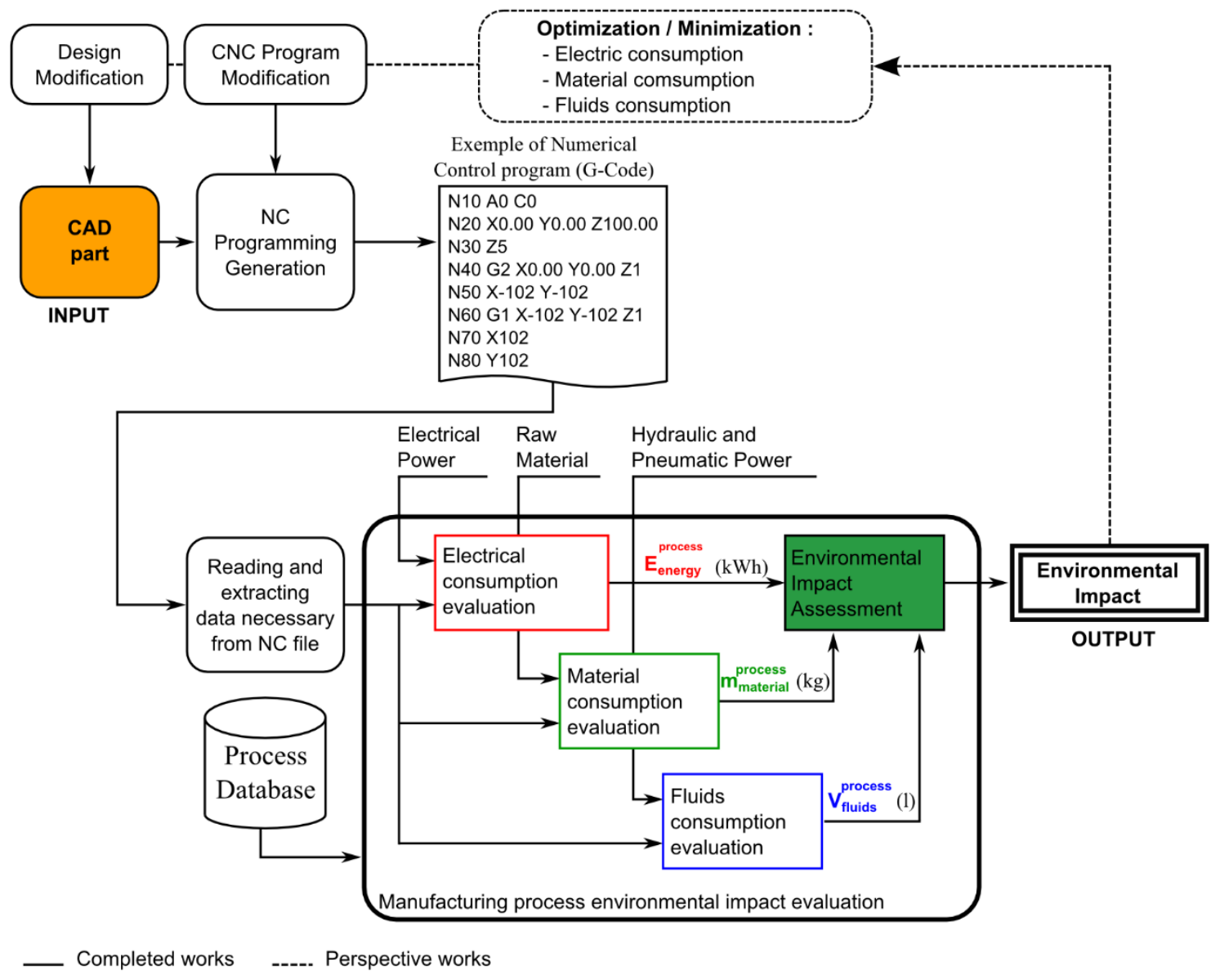

Figure 18. Environmental performance assessment methodology of the set part-process

Different methods can be used to classify the impacts caused on the environment. In this study, the method is Eco-Indicator 99, which is a method oriented damage and translate all the impacts into a unique point value, a non-dimensional number used to compare the different source of impacts [38]. The value of 1 point is defined by a thousandth of the environmental impact caused by a common European during a year. For comparison, the production of $1 \mathrm{~kg}$ of primary steel is around $100 \mathrm{mPts}$ and the production of $1 \mathrm{~kg}$ of stainless steel is around $900 \mathrm{mPts}$. The choice of this method has been done because it was the one that most of studies on environmental assessment of additive processes that have been analyzed in the state-of-the-art used.

This methodology is decomposed into four steps:

- Numerical program generation;

- Extraction of the command parameters;

- Construction of process database;

- Environmental impact assessment.

These steps will be detailed in the next section, which will also give complementary information on the methodology. 


\section{Application to directed energy deposition}

\subsection{Introduction to directed energy deposition process}

This study is based on a directed energy deposition process, known as CLAD process, which manufactures 3D metallic part from CAD model. In this process, a five axes deposition nozzle, where metallic powders are injected into the laser beam, create a small melt pool on the work piece which is cooled down when the laser beam moves on. The part is built as the nozzle moves. Figure 19 shows the design of the nozzle, with laser beam, and an example of a part produced by the machine. The machine is equipped with two kinds of nozzles, which allow to obtain a welding bed from $0.8 \mathrm{~mm}$ (the MesoCLAD nozzle) to $4 \mathrm{~mm}$ (the MacroCLAD nozzle). The machine structure is a five-axis machine-tool (Huron KX8), with its conventional machining spindle (for machining operation such as finishing), in which were added the two nozzles, two powder feeders (for raw material powder) and a 4-kW fiber laser.
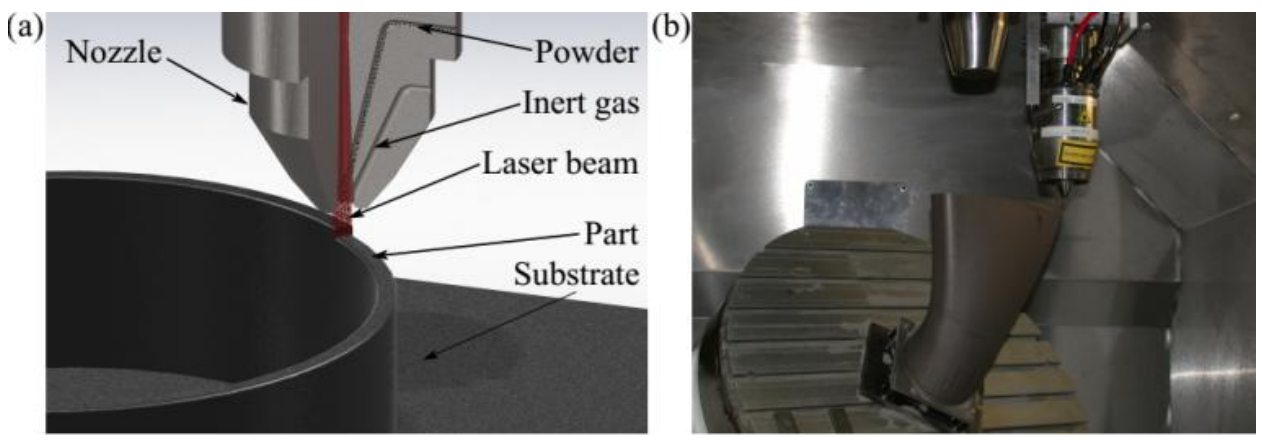

Figure 19. (a) CLAD nozzle design; (b) Example of part produced by this AM process.

\subsection{Atomization of raw material}

The first step for the process is to produce powder (metallic, ceramic, glass) which will be introduced in the machine. An atomization process is used to obtain this powder (Figure 20).

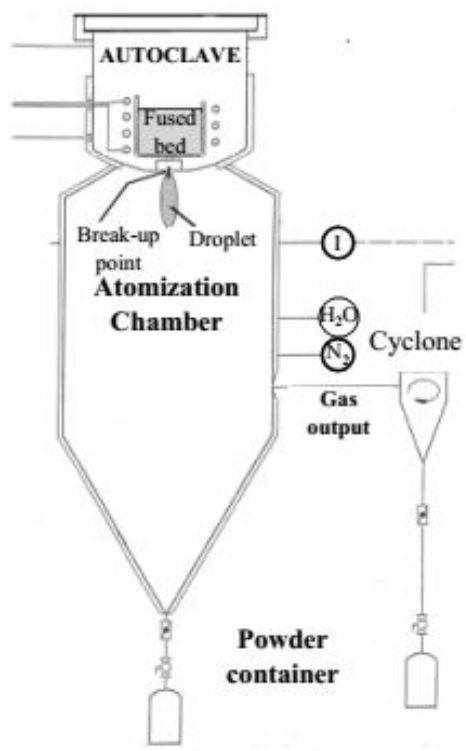

Figure 20. Atomization process. 
In this process, raw materials (from block or cylinder) are heated until melting point in a chamber and then atomized with an inert gas (in the case study: argon). This atomization consists to compress, under high depression, the metallic fluid which will be atomized into small droplet in reaction to depression.

In this process, many values can be saved and it is possible to establish a model for the atomization step. The model is made with experimental values such as:

- Gas consumption,

- Water consumption,

- Electrical consumption.

Table 2 shows all the parameters that have been monitored or calculated during experiments on atomization process in order to build the modeling of the process.

Table 2. Nomenclature for atomization process.

\begin{tabular}{|c|c|c|c|}
\hline Parameters & Name & Units & Saved / Calculated \\
\hline$V_{\text {argon }}$ & Volume of consumed argon & cubic meter & Calculated \\
\hline$d_{\text {argon }}$ & Argon flow rate & $\begin{array}{l}\text { cubic meter } \\
\text { per second }\end{array}$ & Monitored \\
\hline$\rho$ & Gas density & $\begin{array}{l}\text { kilogram per } \\
\text { liter }\end{array}$ & - \\
\hline$V_{\text {water }}$ & Volume of consumed water & liter & Calculated \\
\hline$d_{\text {water }}$ & Water flow rate & $\begin{array}{l}\text { liter per } \\
\text { second }\end{array}$ & Monitored \\
\hline$t_{\text {atomization }}$ & Time for atomization & second & Monitored \\
\hline$E_{\text {electrical }}$ & Electric energy & KWh & Calculated \\
\hline$P_{\text {inductor }}$ & Electrical power of the inductor & Watt & Monitored \\
\hline$P_{\text {depression }}$ & Electrical power of the vacuum system & Watt & Monitored \\
\hline$t_{\text {vacuum }}$ & Total time of the vacuum system ON & second & Monitored \\
\hline$P_{\text {pre-heating }}$ & $\begin{array}{c}\text { Electrical power of the pre-heating } \\
\text { system }\end{array}$ & Watt & Monitored \\
\hline$t_{\text {pre-heating }}$ & Total time of the pre-heating system ON & second & Monitored \\
\hline
\end{tabular}

\subsubsection{Gas consumption}

Gas consumption is linked to the volume of the inert chamber and the atomization step. Figure 21 shows the variation flow of argon in the chamber, during the atomization of $1 \mathrm{~kg}$ of metallic glass. 


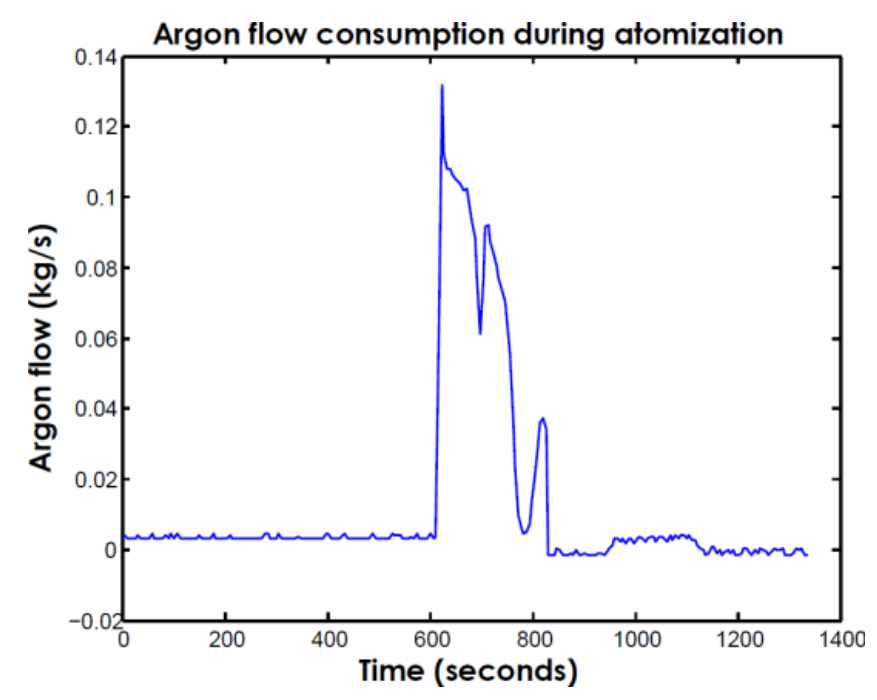

Figure 21. Argon flow consumption.

From this experimental data, an empirical modeling for gas consumption is determined, according to Equation 1.

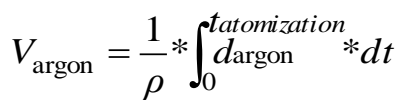

Equation 1.

\subsubsection{Water consumption}

In this system, water runs in close-loop system. However, an amount of used water is released in the nature and a corresponding amount of fresh water is get because the cooling system is not enough efficient. The total volume of consumed water is calculated according to Equation 2.

$$
\begin{gathered}
V_{\text {water }}=d_{\text {water }} * \text { tatomization } \\
\text { Equation } 2 .
\end{gathered}
$$

\subsubsection{Electrical consumption}

Electrical consumption is due to different features of the machine (inductor, pre-heater, vacuum pump). Figure 22 shows a profile of inductor electrical consumption during the atomization process. 


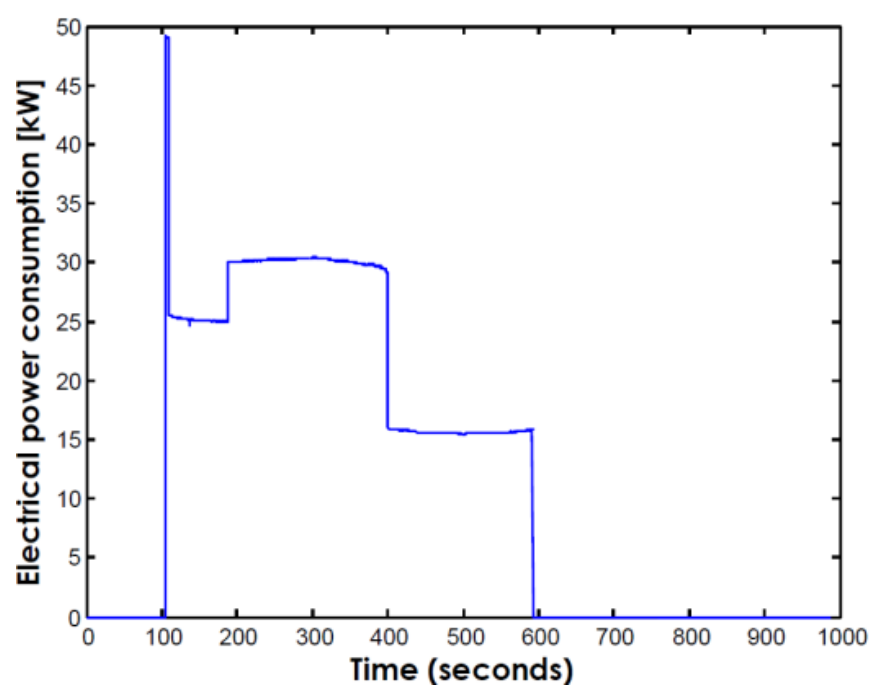

Figure 22. Inductor electrical power consumption during atomization.

From this experimental monitored value, an empirical model for electrical consumption is determined according to Equation 3.

$$
E_{\text {electrical }}=P_{\text {depression }} \times\left(\text { tatomization }+t_{\text {vacuum }}\right)+P_{\text {pre-heating }} \times t_{\text {pre }}-\text { heating }+\int_{0}^{t_{\text {atomization }}} P_{\text {inductor. }} d t
$$

Equation 3.

Table 3 presents the results of the study for $1 \mathrm{~kg}$ of glass powder atomization. This values will help to elaborate the complete environmental assessment.

Table 3. Values of the experiments data monitored and calculated.

\begin{tabular}{|cc} 
Input consumption & Value \\
Gas consumption & $7 \mathrm{~m}^{3}$ \\
\hline Water consumption & 155 liter \\
\hline Electrical consumption & $4 \mathrm{kWh}$ \\
Efficiency & $46 \%$
\end{tabular}

\subsection{Environmental performance modeling for the AM process}

According to the methodology presented in Figure 18 the environmental impacts generated in the manufacturing stage are modeled, from three inputs:

- Electrical consumption

- Material consumption

- Fluids consumption

For each input's consumption, a model based on empiric model or analytical model have been developed. These models allow evaluating the global environmental impact of the part from its CAD model. From CAD model, a G-code file is created which will give the instruction for the machine. From this file, every parameters required to evaluate the environmental impact are extracted.

As well as what have been done for atomization process, Table 4 shows all the parameters monitored during the experiments or calculated. 
Table 4. Nomenclature for directed energy deposition process.

\begin{tabular}{|c|c|c|c|}
\hline Parameters & Name & Units & $\begin{array}{l}\text { Saved / Calculated / } \\
\text { Machine knowledge }\end{array}$ \\
\hline$E I_{i}$ & Environmental impact for substance $i$ & mPts & Calculated \\
\hline$t_{m a n}$ & Manufacturing time & second & Monitored \\
\hline$d_{c}$ & Desired carrying gas & $\begin{array}{l}\text { kilogram per } \\
\text { second }\end{array}$ & Monitored \\
\hline$d_{f}$ & Desired forming gas & $\begin{array}{l}\text { kilogram per } \\
\text { second }\end{array}$ & Monitored \\
\hline $\boldsymbol{k}$ & Weight factor (lost / fused powder) & - & Machine knowledge \\
\hline$d_{p}$ & Powder flow rate & $\begin{array}{l}\text { kilogram per } \\
\text { second }\end{array}$ & Monitored \\
\hline$e_{n}$ & Nozzle efficiency & $\mathrm{KWh}$ & Machine knowledge \\
\hline$g(P l)$ & $\begin{array}{l}\text { Function for laser electrical power } \\
\text { consumption }\end{array}$ & - & Monitored \\
\hline$t_{\text {laser }}$ & $\begin{array}{l}\text { Switch-on time such as } \\
\boldsymbol{t}_{\text {man }}=\boldsymbol{t}_{\text {laser }}+\bar{t}_{\text {laser }}\end{array}$ & second & Monitored \\
\hline$P c_{\text {stand-by }}$ & $\begin{array}{l}\text { Power consumed by the cooling } \\
\text { system in stand-by mode }\end{array}$ & Watt & Monitored \\
\hline$P c_{o n}$ & $\begin{array}{l}\text { Power consumed when the cooling } \\
\text { system works }\end{array}$ & Watt & Monitored \\
\hline$P e_{i}$ & $\begin{array}{l}\text { Electrical power consumed by the } \\
\qquad i \text {-axis }\end{array}$ & Watt & Monitored \\
\hline$P e_{i d l e}$ & Constant electrical power demand & Watt & Monitored \\
\hline
\end{tabular}

For environmental impact assessment, the Eco-Indicator 99 has been used, with the following characterization factors:

- $f c_{\text {argon }}=1.78 \mathrm{mPts} . \mathrm{kg}^{-1}$;

- $f c_{\text {material }}=86 \mathrm{mPts} . \mathrm{kg}^{-1}$;

- $f c_{\text {elec }}=12 \mathrm{mPts} . \mathrm{kWh}$, corresponding to the French electricity production characterization factor.

\subsubsection{Fluids consumptions}

Fluid consumption is due to the inert gas used during the process which allow to project and protect metal powder in the melting pool. In this study, inert gas is argon; it is the same gas for the two functions. Its consumption varied during the manufacturing step and depends on the part morphology. An environmental impact is associated to the inert gas consumption during manufacturing step, according to Equation 4.

$$
\text { E.I.fluids }=\left[d_{c}+d_{f}\right] * t_{\text {man }} * f c_{\text {arg } o n}
$$

Equation 4.

\subsubsection{Material consumption}

Now, the focus is put on the determination of the powder consumption during part manufacturing. In fact, an advantage of additive manufacturing process is to project and fuse 
exclusively the necessary powder. However, this is not the reality and an amount of powder will not be fused in the directed energy deposition process.

In the studied machine, two different kind of nozzles can be used to project the powder. Their efficiency is not the same. Moreover, the efficiency of each nozzle depends on the desired powder flow rate.

An analytic model is proposed for the material consumption estimation during part manufacturing, according to Equation 5.

$$
E I_{\text {material }}=\left[e_{n}+k *\left(1-e_{n}\right)\right] * d_{p} * t_{\text {man }} * f_{c_{\text {material }}}
$$

Equation 5 .

\subsubsection{Electric consumption}

In each machine, electric components can be classified into two categories. Some features have constant energy consumption such as electrical cabinet and hydraulics components. For the other components, their electrical energy consume depend on the part design but also on machine parameters.

The modeling of each feature of the directed energy deposition machine has been done and published by Le Bourhis et al. [39]. In this section, the results are summarized with Equation 6in which can be found the environmental impact of each component.

$$
E_{\text {. } I_{\text {electricit }}}=\left(g(P l) * t_{\text {aser }}+P c_{\text {standby }} * t_{\text {man }}+\left(P c_{o n}-P c_{\text {standby }}\right) * t_{o n}+\left(\sum_{i=1}^{5} \int_{0}^{\text {tman }} P e_{i}(t) * d t\right)+P e_{\text {idle }}\right) * f c_{\text {elec }}
$$

Equation 6.

\subsubsection{Lost powder recycling}

In this process, a non-negligible amount of material is projected but not fused. It seems important to propose a method to recycle this powder. In fact, AM processes could be seen as environmentally friendly only if all the powder projected is used.

The lost powder cannot be used without treatment. In fact, this powder could cause several damages to the machine and need to be sieved and dried before to be reused. Some studies have be conducted to determine that this recycled powder has the same mechanical properties than fresh powder.

\subsection{Industrial example}

\subsubsection{Case study introduction}

This example below will illustrate the possibility of the environmental impact assessment methodology. It is based on a case study presented by Le Bourhis et al. [40].

This example is an aeronautic part which is, at this time produce by conventional machining. More than $80 \%$ of raw material is machined to produce this part. In this example, the focus is on nozzles choice. As it has been previously mentioned, this directed energy deposition process use two kinds of nozzle. Which one is more "environmentally friendly"? The methodology will help to answer this question. 


\subsubsection{CAD part}

The part presented (Figure 23) is composed, amongst others, with a pocket of $200 \mathrm{~mm}$ square and $80 \mathrm{~mm}$ depth. The part thickness is $4 \mathrm{~mm}$. In this study, the answer is how to know which nozzle is better to manufacture the pocket. In fact, it possible to choose in the NC program generation which nozzle will be used.

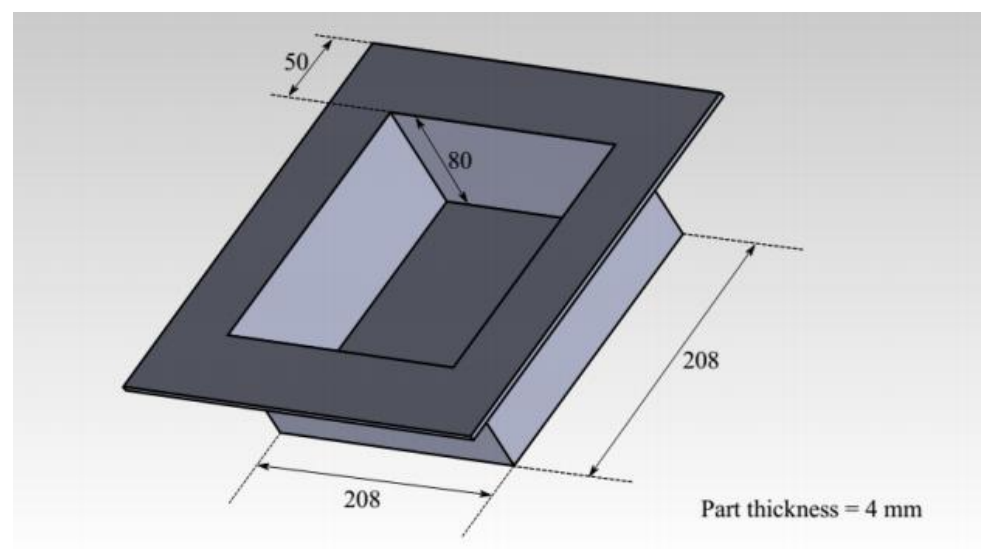

Figure 23. Part model.

\subsubsection{Different manufacturing strategies}

In this case, if the nozzle called MacroCLAD, the part can be produced in one trajectory by layer but the laser power demand will be very high (around $3 \mathrm{~kW}$ ). However, if the smaller nozzle, called MesoCLAD, is used, the part needs five trajectories of $0.8 \mathrm{~mm}$ width by layer with a smaller laser power demand (around $250 \mathrm{~W}$ ). The methodology developed allows to choose which nozzle must be used to minimize the environmental impact of the manufacturing process.

\subsubsection{Environmental impact results}

The model used enable to evaluate the environmental impact of each manufacturing strategy. This methodology is formalized on an informatics tool for designers. The first step is to read the G-code of the CAD model and extract all the values that are needed to evaluate the environmental impact such as laser power, trajectories, axis speed, etc. From these values it is possible to calculate, pre-process, the expected consumptions. The results are given either in scientific units (kWh, liter or kilogram) or in environmental units (mPts). The second unit allows comparing the different flows consumption amongst them.

The results are shown in Figure 24 and Table 5. 


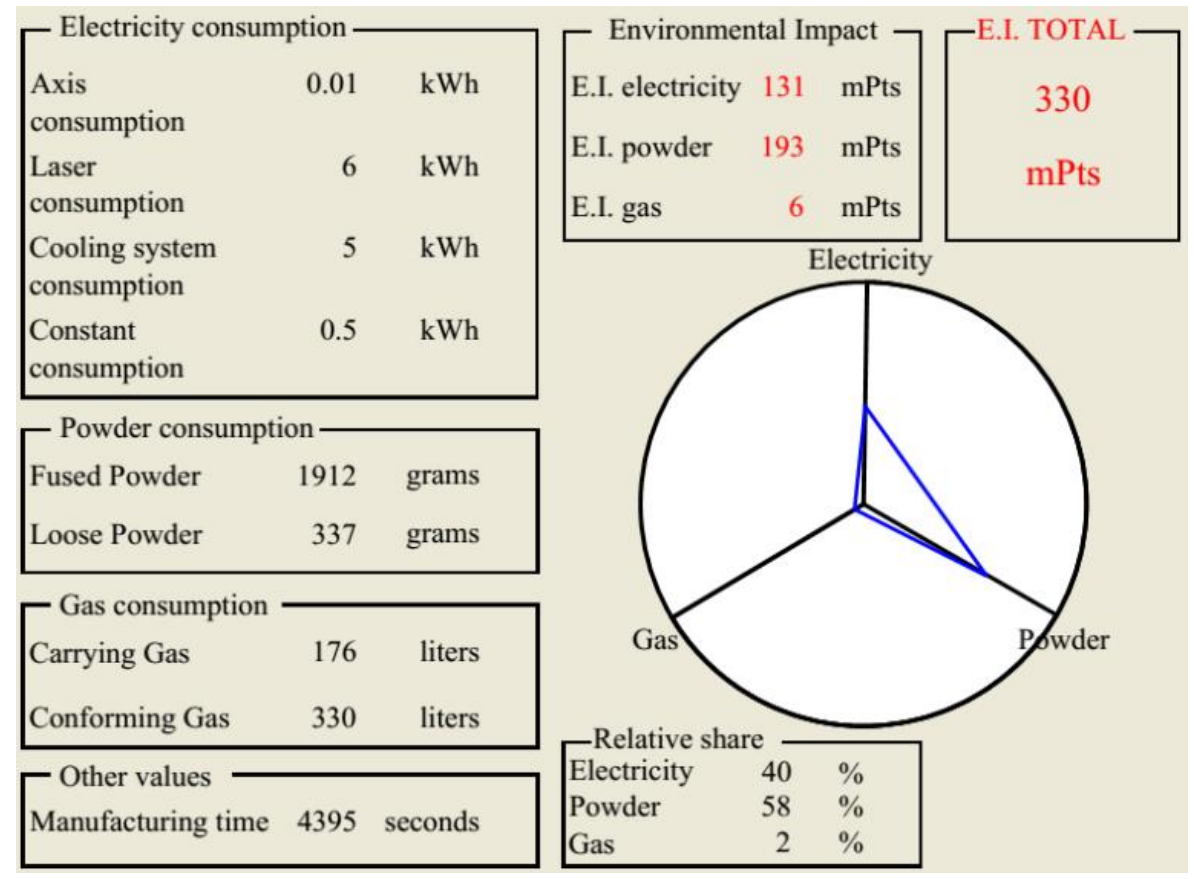

Figure 24. MacroCLAD results.

Table 5. Results of the complete study.

\begin{tabular}{|c|c|c|c|c|}
\hline \multirow{2}{*}{ Input } & \multicolumn{2}{c}{ Scientific units } & \multicolumn{2}{c|}{ Environmental impact } \\
\hline consumption & MacroCLAD & MesoCLAD & MacroCLAD & MesoCLAD \\
\hline Electricity & $12 \mathrm{kWh}$ & $109 \mathrm{kWh}$ & $131 \mathrm{mPts}$ & $1,332 \mathrm{mPts}$ \\
\hline Powder & $2.249 \mathrm{~kg}$ & $3.824 \mathrm{~kg}$ & $193 \mathrm{mPts}$ & $328 \mathrm{mPts}$ \\
\hline Fluids & $0.5 \mathrm{~m}^{3}$ & $9.5 \mathrm{~m}^{3}$ & $6 \mathrm{mPts}$ & $122 \mathrm{mPts}$ \\
\hline Time & $4395 \mathrm{~s}$ & $78,872 \mathrm{~s}$ & & \\
\hline
\end{tabular}

These results show two different kinds of consumption. In fact, even if the power laser demand is more important for MacroCLAD than for MesoCLAD, the total energy consumption to build the same part is less important for MacroCLAD. That is because the time to manufacture the part is drastically reduced when using the MacroCLAD nozzle (in this case study, it obviously depend on the CAD model). Furthermore, the efficiency of the MacroCLAD nozzle is more efficient, around $80 \%$ contrary to $35 \%$ for MesoCLAD. Thus the powder consumption is less important too.

To conclude, the methodology would help the designer to determine, directly from its CAD model, which process could generate the less environmental impact. For this part, it should be interesting to manufacture it with the MacroCLAD nozzle, from an environmental point of view.

\section{Conclusion}

In this chapter, two main points are developed.

First, the literature on all the studies led to characterize the environmental impact of AM processes. The studies on electric energy consumption of these processes are analyzed, 
and then some studies taken into account raw material and all the flows through the process are detailed.

Secondly, a new methodology in order to evaluate, with accuracy, the environmental impact of a part from its CAD model is presented. In this methodology, the work is not focused only on electrical consumption but also on fluids and material consumption which also contribute to the environmental impact. In addition, the inputs of this methodology correspond to the set part-process, which allow taking into account different manufacturing strategies and their influences on the global environmental impact. The methodology developed is based on both analytic models (validated by experiments) and experimental models.

And finally, an industrial example shows that for some manufacturing strategies, the environmental impact due to electrical consumption is not the predominant one. In this case study, material consumption has an important impact and has to be taken into consideration for a complete environmental impact assessment.

\section{References}

[1] J. Kruth, M. Leu, and T. Nakagawa, "Progress in Additive Manufacturing and Rapid Prototyping," CIRP Annals - Manufacturing Technology, vol. 47, no. 2. pp. 525-540, 1998.

[2] D. L. Bourell, M. C. Leu, and D. W. Rosen, "Roadmap for Additive Manufacturing: Identifying the Future of Freeform Processing," 2009.

[3] L. Hao, D. Raymond, G. Strano, and S. Dadbakhsh, "Enhancing the sustainability of additive manufacturing," in ICRM2010 - Green manufacturing, 2010, pp. 390-395.

[4] Y. Luo, Z. Ji, M. C. Leu, and R. Caudill, "Environmental performance analysis of solid freeform fabrication processes," in International Conference on Electronics \& the Environment, 1999, pp. 1-6.

[5] Y. Luo, M. C. Leu, and Z. Ji, "Assessment of environmental performance of rapid prototyping and rapid tooling processes," in Solid Freeform Fabrication Symposium, 1999, pp. 783-792.

[6] R. Sreenivasan and D. L. Bourell, "Sustainability study in selective laser sintering - An energy perspective," in Solid Freeform Fabrication Symposium, 2009, pp. 257-265.

[7] P. Mognol, N. Perry, and D. Lepicart, "Environment aspect of rapid prototyping: process energy consumption," in 12th CIRP Life Cycle Engineering, 2005.

[8] P. Mognol, D. Lepicart, and N. Perry, "Rapid prototyping: energy and environment in the spotlight," Rapid Prototyp. J., vol. 12, no. 1, pp. 26- 34, 2006.

[9] A. Verma and R. Rai, "Energy efficient modeling and optimization of additive manufacturing processes," in Solid Freeform Fabrication Symposium, 2013, pp. 231241.

[10] M. Baumers, C. Tuck, R. Hague, I. Ashcroft, and R. Wildman, "A comparative study of metallic additive manufacturing power consumption," in Solid Freeform Fabrication Symposium, 2010, pp. 278-288.

[11] M. Baumers, C. Tuck, R. Wildman, I. Ashcroft, and R. Hague, "Energy inputs to 
additive manufacturing: Does capacity utilization matter?," in Solid Freeform Fabrication Symposium, 2011, pp. 30-40.

[12] C. Telenko and C. C. Seepersad, "A comparative evaluation of energy consumption of Selective Laser Sintering and Injection Molding of Nylon parts," in Solid Freeform Fabrication Symposium, 1997, pp. 41-54.

[13] C. Telenko and C. C. Seepersad, "Assessing energy requirements and material flows of selective laser sintering of Nylon parts," in Solid Freeform Fabrication Symposium, 2010, pp. 289-297.

[14] E. Atzeni and A. Salmi, "Economics of additive manufacturing for end-usable metal parts," Int. J. Adv. Manuf. Technol., vol. 62, pp. 1147-1155, 2012.

[15] M. Ruffo, C. Tuck, and R. Hague, "Cost estimation for rapid manufacturing - laser sintering production for low to medium volumes," Proc. Inst. Mech. Eng. Part B J. Eng. Manuf., vol. 220, no. 9, pp. 1417-1427, Jan. 2006.

[16] N. Hopkinson and P. Dickens, "Analysis of rapid manufacturing - using layer manufacturing processes for production," J. Mech. Eng. Sci., vol. 217, pp. 31-39, 2003.

[17] W. Morrow, H. Qi, I. Kim, J. Mazumder, and S. Skerlos, "Environmental aspects of laser-based and conventional tool and die manufacturing," J. Clean. Prod., vol. 15, no. 10, pp. 932-943, 2007.

[18] N. Serres, D. Tidu, S. Sankare, and F. Hlawka, "Environmental comparison of MESOCLAD $®$ process and conventional machining implementing life cycle assessment," $J$. Clean. Prod., vol. 19, no. 9-10, pp. 1117-1124, Jun. 2011.

[19] J. Faludi, C. Bayley, S. Bhogal, and M. Iribarne, "Comparing environmental impacts of additive manufacturing vs . traditional machining via life- cycle assessment," 2014.

[20] H.-S. Yoon, J.-Y. Lee, H.-S. Kim, M.-S. Kim, E.-S. Kim, Y.-J. Shin, W.-S. Chu, and S.$\mathrm{H}$. Ahn, "A comparison of energy consumption in bulk forming, subtractive, and additive processes: Review and case study," Int. J. Precis. Eng. Manuf. Technol., vol. 1, no. 3, pp. 261-279, 2014.

[21] G. Strano, L. Hao, K. E. Evans, and R. M. Everson, "Optimisation of quality and energy consumption for additive layer manufacturing processes," in ICRM2010 Green manufacturing, 2010, pp. 364-369.

[22] R. I. Campbell, M. Martorelli, and H. S. Lee, "Surface roughness visualisation for rapid prototyping models," Comput. Des., vol. 34, pp. 717-725, 2002.

[23] G. Strano, L. Hao, R. M. Everson, and K. E. Evans, "Surface roughness analysis modelling and prediction in selective laser melting," J. Mater. Process. Technol., vol. 213, no. 4, pp. 589-597, 2013.

[24] R. Sreenivasan, A. Goel, and D. L. Bourell, "Sustainability issues in laser-based additive manufacturing," Phys. Procedia, vol. 5, pp. 81-90, Jan. 2010.

[25] K. Kellens, E. Yasa, Renaldi, W. Dewulf, J. Kruth, and J. Duflou, "Energy and resource efficiency of SLS/SLM processes," in Solid Freeform Fabrication Symposium, 2011, pp. $1-16$.

[26] K. Dotchev and W. Yusoff, "Recycling of polyamide 12 based powders in the laser sintering process," Rapid Prototyp. J., vol. 15, no. 3, pp. 192-203, 2009.

[27] J. Choren, V. Gervasi, T. Herman, S. Kamara, and J. Mitchell, "SLS powder life study," in Solid Freeform Fabrication Symposium, 2001, pp. 39-45.

[28] K. Kellens, W. Dewulf, M. Overcash, M. Z. Hauschild, and J. R. Duflou, "Methodology for systematic analysis and improvement of manufacturing unit process life-cycle 
inventory (UPLCI)-CO2PE! initiative (cooperative effort on process emissions in manufacturing). Part 1: Methodology description," Int. J. Life Cycle Assess., Oct. 2011.

[29] K. Kellens, E. Yasa, W. Dewulf, and J. R. Duflou, "Environmental assessment of selective laser melting and selective laser sintering," in Going green - CARE Innovations, 2010, no. Section 4.

[30] K. Kellens, E. Yasa, Renaldi, W. Dewulf, J. P. Kruth, and J. R. Duflou, "Energy and resource efficiency of SLS/SLM processes," in Solid Freeform Fabrication Symposium, 2011, pp. 1-16.

[31] K. Kellens, R. Renaldi, W. Dewulf, J. Kruth, and J. R. Duflou, "Environmental impact modeling of selective laser sintering processes," Rapid Prototyp. J., vol. 20, no. 6, pp. 459-470, 2014.

[32] K. Kellens, "Energy and resource Efficient Manufacturing - Unit process analysis and optimisation," KU Leuven, 2013.

[33] R. Hague and C. Tuck, "ATKINS: Manufacturing a Low Carbon Footprint - Zero Emission Enterprise Feasibility Study," 2007.

[34] P. Reeves, "Does additive manufacturing really cost the earth - Stimulating AM adoption through economic \& environmental sustainability," in TCT, 2011.

[35] "ISO 14955-1: Machine tools - Environmental evaluation of machine tools, Part 1: Design methodology for energy-efficient machine tools." 2014.

[36] L. Kroll, P. Blau, M. Wabner, U. Frieß, J. Eulitz, and M. Klärner, "Lightweight components for energy-efficient machine tools," CIRP J. Manuf. Sci. Technol., vol. 4, no. 2, pp. 148-160, Jan. 2011.

[37] T. A. L. Nguyen Thi Ai, M. Museau, and H. Paris, "Methodology for design for energy efficiency of production system," in IDMME -- Virtual Concept -- Improve -- Ingegrag conference, 2014.

[38] M. Goedkoop and R. Spriensma, "The Eco-Indicator 99 Methodology," 1999.

[39] F. Le Bourhis, O. Kerbrat, J.-Y. Hascoet, and P. Mognol, "Sustainable manufacturing: Evaluation and Modeling of environmental impacts in additive manufacturing," Int. J. Adv. Manuf. Technol., vol. 69, pp. 1927-1939, 2013.

[40] F. Le Bourhis, O. Kerbrat, L. Dembinski, J. Hascoet, and P. Mognol, "Predictive model for environmental assessment in additive manufacturing process," in 21st CIRP Conference on Life Cycle Engineering, 2014, pp. 1-6. 